\title{
Generating a Precision Endoxifen Prediction Algorithm to Advance Personalized Tamoxifen Treatment in Patients with Breast Cancer
}

\author{
Thomas Helland ${ }^{1,2,3, *(D)}$, Sarah Alsomairy ${ }^{1}$, Chenchia Lin ${ }^{1}$, Håvard Søiland ${ }^{3}$, Gunnar Mellgren ${ }^{2,3}$ \\ and Daniel Louis Hertz ${ }^{1}$ (D)
}

1 Department of Clinical Pharmacy, University of Michigan College of Pharmacy, Ann Arbor, MI 48109, USA; salsmry@med.umich.edu (S.A.); linchenc@med.umich.edu (C.L.); DLHertz@med.umich.edu (D.L.H.)

2 Hormone Laboratory, Department of Medical Biochemistry and Pharmacology, Haukeland University Hospital, 5021 Bergen, Norway; gunnar.mellgren@uib.no

3 Department of Clinical Science, University of Bergen, 5007 Bergen, Norway; hsoiland@gmail.com

* Correspondence: thomas.helland@uib.no; Tel.: +47-92847793

check for

updates

Citation: Helland, T.; Alsomairy, S.; Lin, C.; Søiland, H.; Mellgren, G.; Hertz, D.L. Generating a Precision Endoxifen Prediction Algorithm to Advance Personalized Tamoxifen Treatment in Patients with Breast Cancer. J. Pers. Med. 2021, 11, 201. https://doi.org/10.3390/ jpm11030201

Academic Editor: Alan L. Myers

Received: 18 February 2021

Accepted: 9 March 2021

Published: 13 March 2021

Publisher's Note: MDPI stays neutral with regard to jurisdictional claims in published maps and institutional affiliations.

\begin{abstract}
Tamoxifen is an endocrine treatment for hormone receptor positive breast cancer. The effectiveness of tamoxifen may be compromised in patients with metabolic resistance, who have insufficient metabolic generation of the active metabolites endoxifen and 4-hydroxy-tamoxifen. This has been challenging to validate due to the lack of measured metabolite concentrations in tamoxifen clinical trials. CYP2D6 activity is the primary determinant of endoxifen concentration. Inconclusive results from studies investigating whether CYP2D6 genotype is associated with tamoxifen efficacy may be due to the imprecision in using CYP2D6 genotype as a surrogate of endoxifen concentration without incorporating the influence of other genetic and clinical variables. This review summarizes the evidence that active metabolite concentrations determine tamoxifen efficacy. We then introduce a novel approach to validate this relationship by generating a precision endoxifen prediction algorithm and comprehensively review the factors that must be incorporated into the algorithm, including genetics of CYP2D 6 and other pharmacogenes. A precision endoxifen algorithm could be used to validate metabolic resistance in existing tamoxifen clinical trial cohorts and could then be used to select personalized tamoxifen doses to ensure all patients achieve adequate endoxifen concentrations and maximum benefit from tamoxifen treatment.
\end{abstract}

Keywords: endoxifen; 4OHtam; tamoxifen metabolism; CYP2D6; pharmacogenetics; SULT; UGT; CYP3A; CYP2C; personalized treatment

\section{Introduction and Objective}

Tamoxifen is an endocrine drug that has significantly improved outcomes in hormone receptor positive breast cancer [1]. However, the 10-year recurrence rate in patients using tamoxifen is $\sim 30 \%$ [1]. Tamoxifen is a weak anti-estrogen that requires metabolic conversion to active metabolites that have higher affinity to the estrogen receptor (ER). This conversion is mediated by several cytochrome P450 (CYP) enzymes in which CYP2D6 plays a central role in the generation of the main active metabolite endoxifen [2]. Diminished CYP2D6 phenotypic activity is associated with lower levels of endoxifen [2,3] that may reduce treatment response [4], which we refer to as metabolic resistance [4-6]. However, few large clinical trials have measured endoxifen concentration, preventing confirmation of metabolic resistance or identification of an endoxifen threshold below which efficacy is compromised. Many studies have investigated the association of tamoxifen treatment outcomes with CYP2D6 genotype, as a surrogate of endoxifen concentration (Figure 1). The inconclusive findings [7] from these analyses may be due to the imprecision in predicting endoxifen from only CYP2D6 genotype [8]. 
This review comprehensively reviews the factors that contribute to imprecision in endoxifen prediction by CYP2D 6 and describes the contribution of other non-CYP2D6 genetic and clinical factors to endoxifen concentrations. The objective of this review is to provide a better understanding of these factors to move this field away from the use of a single genotype (CYP2D6) and toward building a precision endoxifen prediction model that integrates genetic and clinical variables. This algorithm could enable definitive analyses of the association of endoxifen concentration with tamoxifen treatment effectiveness and could then be used for personalized tamoxifen dosing to ensure that all patients achieve target endoxifen concentrations and receive maximum benefit from tamoxifen treatment.

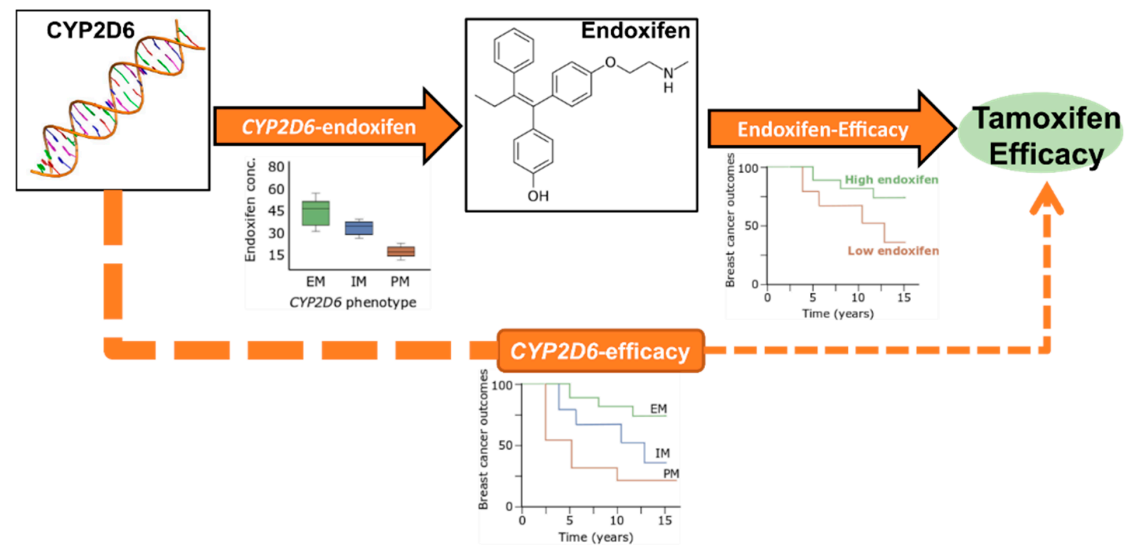

Figure 1. Approaches for investigating metabolic resistance in breast cancer patients. The CYP2D6endoxifen relationship is well established. The endoxifen-efficacy relationship has been reported but not sufficiently validated due to a lack of available data. The CYP2D6-efficacy relationship has not been conclusively demonstrated due to the imprecision in using CYP2D6 as a surrogate of endoxifen concentration. Box plot and survival curves are for illustration purposes only. $\mathrm{EM}=$ Extensive Metabolizer, $\mathrm{IM}=$ Intermediate Metabolizer, $\mathrm{PM}=$ Poor Metabolizer.

\section{Tamoxifen Clinical Use, Metabolism and Metabolic Resistance}

\subsection{Tamoxifen Treatment and Mechanism of Action}

Tamoxifen is a selective estrogen receptor modulator used in the treatment and prevention of hormone receptor positive breast cancer. In the adjuvant setting, tamoxifen ( $20 \mathrm{mg} /$ day) is mainly indicated for premenopausal patients with a recommended treatment time of 5 years that may also be extended to 10 years [1,9]. Although the overall reduction in mortality from tamoxifen treatment is substantial, the recurrence rate reduction remains about $50 \%$ during treatment and one-third in the subsequent five years [1], with some patients experiencing treatment failure. Tamoxifen may also be used to reduce the risk of developing breast cancer in high-risk women with or without neoplastic events $[10,11]$.

The rationale for tamoxifen treatment of hormone receptor positive breast cancer is to prevent transcription of ER-regulated genes involved in breast cancer differentiation, proliferation, and migration [12]. Tamoxifen's mechanism of action involves binding the ligand binding pocket of the ER that promotes a conformational change preventing recruitment of coactivators and instead cause association with corepressors thus repressing transcriptional activity of the ER $[13,14]$. This process takes place because tamoxifen has a higher affinity to the ER than does estradiol (E2), its natural ligand.

\subsection{Tamoxifen Metabolism}

Tamoxifen has a highly lipophilic structure and has been shown to be $98 \%$ albumin bound, which contributes to its long half-life of around 7 days [15]. Steady state levels are reached within 4-8 weeks [16]. Upon oral administration, some first pass metabolism occurs in the small intestine [15] but the majority of tamoxifen metabolism occurs in the liver and follows the classic two phases. Phase I hepatic metabolism of tamoxifen involves 
the addition or removal of certain functional groups through $\mathrm{N}$-oxidation, hydroxylation or demethylation catalyzed by various members of the cytochrome P450 (CYP) family of enzymes [17] (Figure 2). The metabolites formed directly from tamoxifen are described as primary metabolites. The major route of phase I tamoxifen metabolism is demethylation of tamoxifen to N-desmethyl-tamoxifen (NDtam) catalyzed primarily by CYP3A4/5, in addition to CYP2C19/9, CYP1A2 and CYP2D6 $[17,18]$. NDtam is the major metabolite of tamoxifen and its plasma concentrations are approximately double that of the parent tamoxifen at steady state [3,19]. An alternative and minor route involves hydroxylation of tamoxifen to the active metabolite 4-hydroxy-tamoxifen (4OHtam) catalyzed by CYP2D6, CYP2C9/19, CYP2B6 and CYP3A4 [20]. Other primary metabolites include 3-hydroxytamoxifen (3-OHtam), tamoxifen-N-oxide (tam-NoX) and $\alpha$-hydroxy-tamoxifen [17,21].

The main active metabolite of tamoxifen, 4-hydroxy-N-desmethyl-tamoxifen, hereby and earlier referred to as endoxifen, is a secondary metabolite formed by hydroxylation of NDtam catalyzed by CYP2D6 alone and by demethylation of 4OHtam to endoxifen by CYP3A4/5, CYP2C19 and CYP2D6 [17]. Secondary metabolites such as Ndidesmethyl-tamoxifen (N,N-DDtam), 3-hydroxy-N-desmethyl-tamoxifen (3OHNDtam) and $\mathrm{N}, \mathrm{N}$-didesmethyl-4-hydroxy-tamoxifen (norendoxifen) are also formed from the primary or secondary metabolites [22], however their affinity and ER-inhibition are minor or yet to be determined (Table 1).

The phase I metabolites are further conjugated by glucuronidation [21,23] or sulfation [24] in hepatic phase II metabolism reactions catalyzed by uridine glucuronosyltransferases (UGTs) and sulfotransferases (SULTs), respectively [25]. Conjugation deactivates metabolites and increases their water solubility for excretion via bile or urine, however as much as $69 \%$ of the metabolites in the bile are reabsorbed by enterohepatic recirculation $[26,27]$.

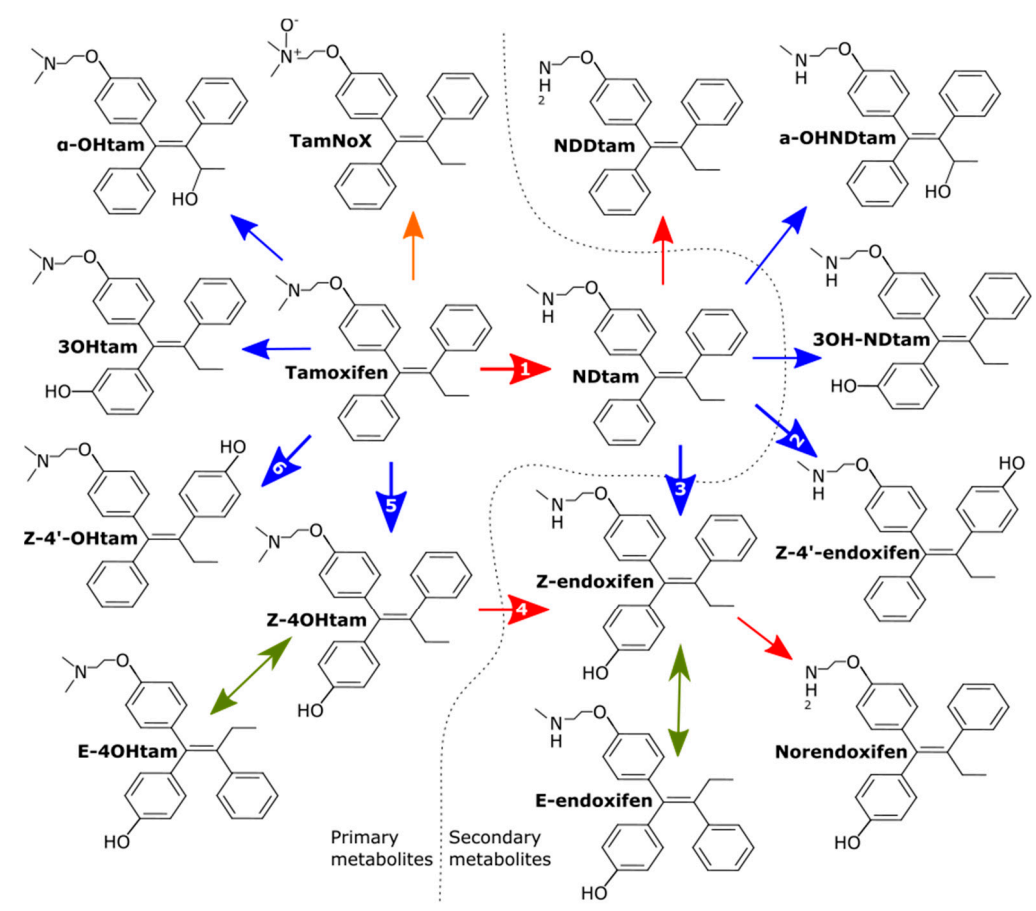

Figure 2. Overview of tamoxifen metabolites formed during first phase hepatic metabolism. Only isomers of $4 \mathrm{OH}$ tam and endoxifen are shown, other metabolites may also be subject to isomerism. Blue, red, orange, and green lines represent hydroxylation, demethylation, N-oxidation and nonenzymatic isomerization, respectively. Numbered arrows represent the following CYP450 enzymes involved in generation of active metabolites and their less active isomers: (1) CYP3A4/5, CYP1A1/2, CYP2C9/19, CYP2D6 (2) Unknown (3) CYP2D6 (4) CYP3A4/5, CYP2C19, CYP2D6. (5) CYP2C9/19, CYP2D6, CYP3A4, CYP2B6 (6) CYP2B6, CYP2D6. Modified from [28]. 


\subsection{Active Metabolites: 4 OHtam and Endoxifen}

Tamoxifen is regarded as a prodrug as several of its metabolites have higher ER affinity and these metabolites may be responsible for the overall anti-estrogenic effect. Two of these metabolites (4OHtam and endoxifen) have up to $100 \times$ higher affinity to the ER compared to the parent drug tamoxifen $[29,30]$ and are referred to as active metabolites (Table 1). Both active metabolites (4OHtam and endoxifen) may be formed as different isomers (E and $\mathrm{Z}$ isomers), in which the Z-isomers have $>99 \%$ higher affinity to the ER compared to the E-isomers [31]. Adding to the complexity, the position of the hydroxyl group on the rings of hydroxylated metabolites may also vary. Z-endoxifen or Z-4OHtam with the hydroxyl group on the secondary structure, are referred to as $4{ }^{-}{ }^{-}$-isomers or 4-prime-isomers (i.e., Z-4'-endoxifen and Z-4'-OHtam). The Z-4'-isomers exhibit $~ 10 \%$ of the binding affinity to the ER compared to the Z-isomers [32].

The more potent anti-estrogenic action of endoxifen and 4OHtam compared to tamoxifen itself is caused by the presence and position of the phenolic hydroxyl in their structures. In short, the positioning of the phenol group ensures deeper penetration into the binding pocket of the ER causing conformational changes in the ligand binding domain and correct positioning of the bulky side chain for antagonistic conformation of the ER $[13,33]$. The two active metabolites have similar affinity to the ER and similar anti-estrogenic effect on breast cancer cell proliferation [34]. However, since endoxifen plasma levels exceed $4 \mathrm{OHtam}$ by $5-10 \times$ it is regarded as the most important active metabolite. In contrast to $4 \mathrm{OHtam}$, endoxifen has been shown to induce proteasomal degradation of the ER [35]. The same in vitro study also indicated that endoxifen induces highly concentration-dependent effects in blocking of ER $\alpha$ transcriptional activity and inhibition of estrogen-induced breast cancer cell proliferation, even in the presence of physiologically relevant concentrations of tamoxifen, NDtam, and 4OHtam [35]. Tumor growth inhibition in mouse models treated with endoxifen have also been shown to be highly concentration dependent [36]. Although other metabolites such as the 3-hydroxylated metabolites have been reported to have anti-estrogenic activity, their concentrations in vivo are generally too low to demonstrate any noteworthy antagonistic effect on the ER and to this point no other highly active metabolites have been described [28].

Table 1. Relative ER affinity and abundance of tamoxifen metabolites.

\begin{tabular}{ccc}
\hline Metabolite & Relative ER Affinity & Relative Abundance \\
\hline Tamoxifen & 1 & 1 \\
Tam-NoX & n.d & 0.07 \\
3OHtam & 10 & $<0.01$ \\
Norendoxifen & n.d & \\
$\alpha$-OHtam & n.d & $<0.01$ \\
NDtam & 0.85 & $1.78-2.01$ \\
NNDDtam & 0.46 & $0.29-0.22$ \\
3OHNDtam & n.d & $<0.01$ \\
Z-4OHtam & & \\
Z-4'-Ohtam & 100 & $0.01-0.02$ \\
E-4OHtam & 10 & $0.02-0.03$ \\
4OHtam Isoforms & $<0.03$ & $<0.01$ \\
Z-endoxifen & & \\
Z-4'-endoxifen & 100 & $0.07-0.09$ \\
E-endoxifen & 10 & $0.05-0.08$ \\
Endoxifen Isoforms & $<0.03$ & $<0.01$ \\
\hline
\end{tabular}

Affinity and abundance are relative to tamoxifen. Data on ER affinity was obtained from [31,32,34,37,38]. Information on abundance was extracted from studies using highly specific and selective LC-MS/MS assays [28,39]. n.d $=$ not determined . 


\subsection{Associations of Active Metabolite Concentrations with Tamoxifen Efficacy}

In addition to the pharmacological and pre-clinical evidence suggesting that concentrations of active metabolites are associated to the anti-estrogenic effect of tamoxifen, there is also evidence from clinical studies suggesting that active metabolite concentrations determine tamoxifen efficacy $[4-6,40]$. Three separate retrospective studies of patients treated with adjuvant tamoxifen have identified an association between low serum levels of endoxifen and inferior breast cancer outcome $[4,5,40]$. Two of the studies [4,5] identified similar thresholds of $16 \mathrm{nM}$ and $14.15 \mathrm{nM}$, while the third study reported a lower threshold of $9 \mathrm{nM}$ endoxifen [40]. Another small explorative study of 48 Asian women with breast cancer demonstrated a J-shaped relationship in which patients with endoxifen levels $<53.6 \mathrm{nM}$ and $>187.4 \mathrm{nM}$ were at higher risk of recurrence [41].

The first prospective study designed specifically to investigate metabolic tamoxifen resistance [42] found no association between relapse free survival and endoxifen levels as a continuous variable, quartiles or after applying the $16 \mathrm{nM}$ threshold in 667 patients with early-stage breast cancer. However, heavy censoring due to patients switching to Aromatase Inhibitors (AIs) may have reduced the power of the survival analyses [43,44]. Metabolic resistance has also been investigated in the metastatic setting in two recent prospective studies. In 247 patients with metastatic breast cancer receiving $20 \mathrm{mg}$ tamoxifen as first- or second-line treatment, no association was found between endoxifen concentration and overall response rate, progression free survival, or clinical benefit [45]. A secondary analysis of a prospective, randomized phase II trial investigating the clinical benefit of tamoxifen dose escalation in patients expected to have low endoxifen concentrations due to their CYP2D6 genotype, as explained later, found similar endoxifen concentrations in patients who had and had not progressed after 6 months [46].

The relationship between endoxifen concentrations and outcome has also been explored in the preventive setting in high-risk women receiving low-dose tamoxifen, however no association between endoxifen concentrations and neoplastic events was identified in 97 premenopausal patients treated with $5 \mathrm{mg}$ tamoxifen for 2 years [47]. A recent randomized placebo-controlled trial of low dose tamoxifen ( $5 \mathrm{mg} /$ day) in the preventive setting [11] showed similar prophylactic effect of $5 \mathrm{mg}$ tamoxifen as what has previously been reported for $20 \mathrm{mg}$, indicating that low endoxifen concentrations may still be effective in the preventive setting.

It has also been reported that patients with $4 \mathrm{OHtam}<3.26 \mathrm{nM}$ have inferior breast cancer specific survival [40] and the threshold was recently confirmed in an independent patient cohort [6]. A simulation study found that inclusion of $4 \mathrm{OHtam}$ into an antiestrogenic activity score was predictive of survival [37], but not superior to using endoxifen levels alone [4].

Due to the heterogeneity in the results described above, it is still not fully established that active metabolite levels are predictive of tamoxifen efficacy. However, metabolic resistance is likely most relevant in the adjuvant setting as the most consistent results were reported from studies analyzing patients treated adjuvantly with tamoxifen alone for 5 years. All three retrospectively determined endoxifen thresholds $[4,5,40]$ and the identification [40] and validation [6] of the 4OHtam threshold were conducted in the adjuvant setting. In addition, all these studies had long-term follow up, allowing for inclusion of late recurrences ( $>5$ years) which make up the majority of the relapses in ER positive breast cancer [48]. Inability to prospectively validate metabolic resistance in the adjuvant setting $[42,49]$ may be due to a preponderance of early relapses $(<3$ years) that are frequently attributable to proliferative factors such as high Ki67 [50], and to the contribution of endocrine resistance from somatic ER gene (ESR1) mutations [51], epigenetics [52] or loss of ER [53]. 
A well-powered adjuvant study with long-term follow-up that excludes recurrence events caused by somatic ER mutations or loss of ER may be necessary to validate insufficient metabolite concentrations as a biomarker for ineffective tamoxifen therapy. Since such a study may never again be attempted, an alternative approach is necessary. One such potential approach may be to use the currently available studies with measured endoxifen concentrations to build a precision endoxifen algorithm that integrates clinical and genetic variables to predict steady state endoxifen concentrations in individual patients (Figure 3). That algorithm could then be used to retrospectively test whether predicted endoxifen concentration is associated with recurrence or survival in prospective tamoxifen clinical trials with long-term follow-up that do not have measured endoxifen concentrations including the Breast International Group 1-98 (BIG1-98) [54] and Arimidex, Tamoxifen, Alone or in Combination (ATAC) trials [55]. Upon validation of the association and determination of the target endoxifen concentration threshold, this algorithm could be used to select an appropriate starting dose of tamoxifen to ensure all patients achieve therapeutic endoxifen concentrations and receive maximal tamoxifen treatment benefit.

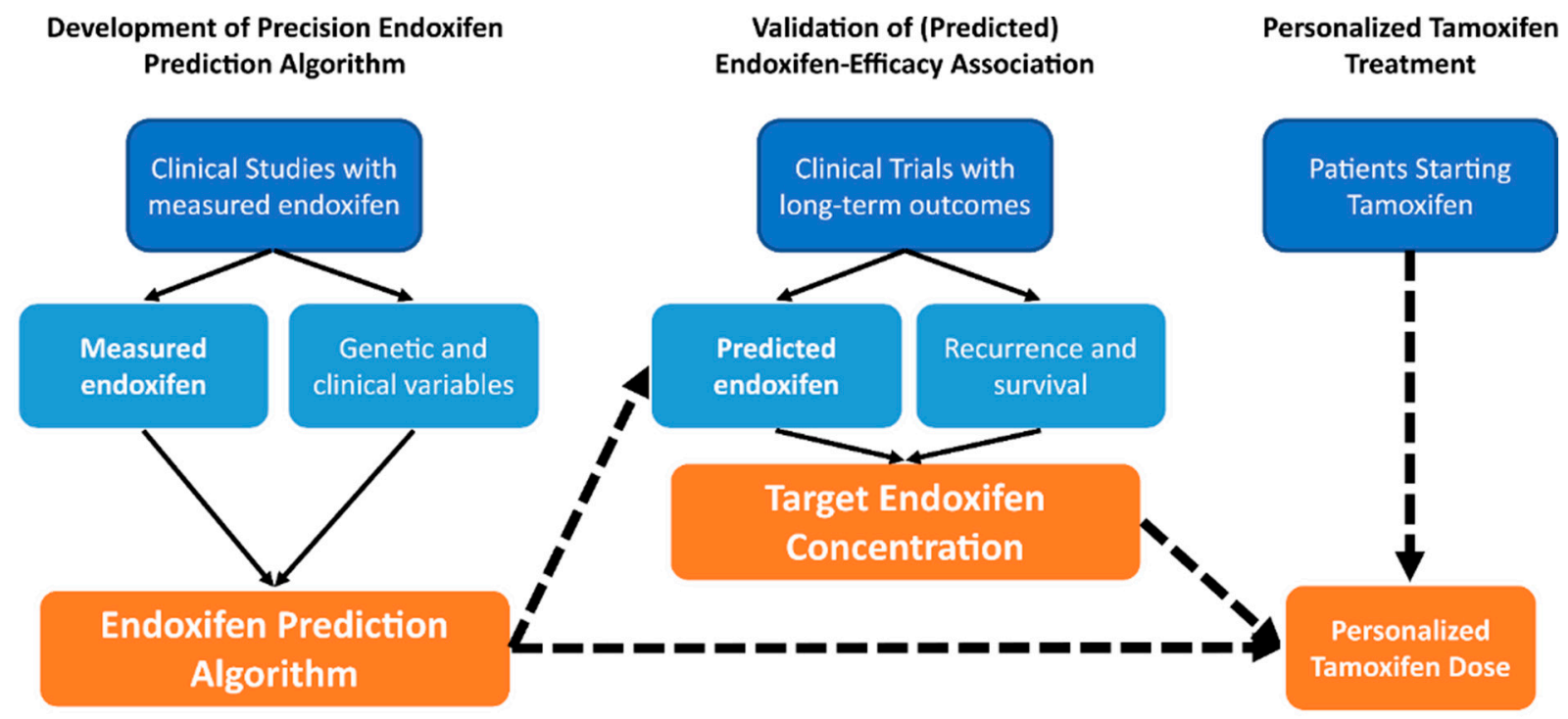

Figure 3. Approach for generating a precision endoxifen prediction algorithm to enable personalized tamoxifen dosing. A precision endoxifen prediction algorithm that integrates clinical and genetic variables could be generated from existing datasets. The algorithm would then be used to validate the association of endoxifen concentration with tamoxifen efficacy and identify the target endoxifen concentration. This information could then be used to inform personalized dosing that maximizes tamoxifen treatment efficacy.

\section{Prediction of Active Tamoxifen Metabolite Concentrations}

\subsection{Genotype-Predicted Endoxifen Concentrations and Tamoxifen Treatment Efficacy}

As most studies do not have endoxifen concentrations available, an alternative approach has been to use genetic variations in the pharmacogene CYP2D6 as a surrogate of endoxifen concentrations to investigate the endoxifen-efficacy association. Over 30 studies have applied this approach and have produced heterogenous results, extensively reviewed elsewhere [7], which have led to conflicting clinical recommendations on the utility of CYP2D6 genotyping to inform tamoxifen dosing [7,56-58]. The inconsistent CYP2D6efficacy results may be due to the imprecision in estimating endoxifen. In the following sections we will review factors that improve endoxifen prediction accuracy, including comprehensive CYP2D6 genotyping, standardized phenotype translation, and awareness of tamoxifen adherence and concomitant CYP2D6 inhibitor-use. Endoxifen prediction could be further enhanced by accounting for the contribution of other pharmacogenes involved in tamoxifen metabolism including CYP2Cs, CYP3As, UGTs and SULTs, which have been investigated for association with tamoxifen treatment outcomes with similarly 
heterogenous results $[8,55,59,60]$. The following sections will review the studies that have reported associations with endoxifen concentration and highlight the factors that need to be considered when developing a precision endoxifen prediction algorithm.

\subsection{Effect of CYP2D6 on Endoxifen Formation}

CYP2D6 is the central enzyme in the metabolic bioactivation of tamoxifen by catalyzing the addition of a hydroxyl group to the phenyl ring of NDtam thereby forming the active metabolite endoxifen [23]. As the demethylation of tamoxifen to NDtam is the major route of tamoxifen metabolism $(\sim 90 \%)$ the quantitative contribution of CYP2D6 in endoxifen formation is significantly higher than the alternative minor route of endoxifen formation through demethylation of $4 \mathrm{OH}$ tam which involves several enzymes [18]. For this reason, CYP2D6 metabolic activity is the major determinant of endoxifen generation.

\subsubsection{CYP2D6 Genetic Variation and Activity Phenotype Translation}

The CYP2D6 gene is located on chromosome 22q13.1 and is highly polymorphic with over 100 allelic variants/haplotypes known [61]. These germline variations include Single Nucleotide Variants (SNVs), insertions or deletions of single or multiple nucleotides, copy number variations or other structural variations that may result in splicing defects, frameshifts, whole gene deletions or changes in gene expression. This may lead to abnormal protein expression or function and consequently impact CYP2D6 metabolic activity, and thereby affect the formation of endoxifen.

CYP2D6 allelic haplotypes are classified according to the star allele nomenclature [62]. Each star allele has a designated functional activity and activity score provided by PharmVar [62] which is used to determine the metabolizer phenotype by combining the functional activity of haplotypes into diplotypes. In the star allele system, an allelic haplotype with pharmacogenomic relevance is classified by the gene name followed by a star and a number (e.g., CYP2D $6^{*} 4$ ). The allelic haplotype usually refers to a group of variants that tend to be inherited together, in which one or more of the genetic variants affects protein activity. Several additional variants that are not known to influence activity may also be part of the star allele and may define subvariants (e.g., $C Y P 2 D 6^{*} 2 B$ ). Importantly, the core alleles will be part of all sub alleles and ensures that all sub alleles can be combined into a single a star number with functional relevance, whereas the non-consequential alleles may be shared across star alleles and should not be used to define star alleles. There are two notable limitations of interpreting studies that use the star allele system, or any other pharmacogenetic system. First, the star allele is not substrate specific and the values for the metabolic activity are not determined exclusively based on data from tamoxifen metabolism studies. Recent consensus CYP2D6 guidelines highlight the potential to enhance accuracy in scoring metabolic activity using a quantitative, substrate-specific percentage activity system [63]. Second, studies test for a defined list of CYP2D6 genetic variations and, by default, classify all non-carriers as wild-type $\left(C Y P 2 D 6^{*} 1\right)$ when they may in fact carry another functionally consequential variant that was untested. Prior pharmacogenetic studies have used a variety of approaches for translating CYP2D6 genotype into metabolic activity phenotype [64] but recently two major pharmacogenetic consortiums and a panel of experts agreed to a consensus scoring system [63] (Table 2). 
Table 2. Activity Score System.

\begin{tabular}{ccccc}
\hline & Allelic Activity Scoring & \multicolumn{2}{c}{ Metabolic Phenotype Scoring } \\
\hline Activity & Genotype Examples & Activity Score & Activity Score Sum & Phenotype \\
\hline High & ${ }^{*} 1 \mathrm{XN},{ }^{*} 2 \mathrm{XN},{ }^{*} 35 \mathrm{XN}$ & 2 & $>2.25$ & $\mathrm{UM}$ \\
\hline Normal & $* 1, * 2$, and $* 35$ & 1 & $1.25-2$ & $\mathrm{NM}$ \\
\hline Reduced & $* 9, * 17, * 29, * 36, * 41$ & 0.5 & $0.25-1$ & $\mathrm{IM}$ \\
\hline Slow & $* 10$ & 0.25 & $0.25-1$ & $\mathrm{IM}$ \\
\hline None & $* 3, * 4, * 5, * 6, * 7, * 8$ & 0 & 0 & $\mathrm{PM}$ \\
\hline
\end{tabular}

$\overline{\mathrm{UM}}=$ Ultra-rapid Metabolizer, NM = Normal Metabolizer, IM = Intermediate Metabolizer, PM = Poor Metabolizer

\subsubsection{Effect of CYP2D6 Genetic Variation on Endoxifen Concentrations}

The association between CYP2D6 genotype and endoxifen concentrations was first described by Stearns and colleagues [2] in a pilot clinical trial in 2002. In this small study $(n=12)$, patients with CYP2D6 non-functional variants $\left({ }^{*} 4,{ }^{*} 6,{ }^{*} 8\right)$ had significantly lower levels of endoxifen compared to patients not harboring these variants (wild type). Two subsequent studies $[3,65]$ reported $30 \%$ and $74 \%$ reductions in endoxifen concentrations for patients homozygous for non-functional alleles $\left({ }^{*} 3,{ }^{*} 4,{ }^{*} 5,{ }^{*} 6\right)$ compared to wild type. Taken together, these three early studies showed that patients using tamoxifen carrying CYP2D6 non-functional alleles have significantly reduced levels of endoxifen. To date, more than 30 studies have investigated this association and CYP2D6 genotype is now an established predictor of endoxifen concentrations (Table 3). These studies have found that $8 \%$ to $46 \%$ of endoxifen concentration variability can be explained by CYP2D6 genotype (regression $R$ squared values). The higher endoxifen estimates are likely representative of the actual contribution of $C Y P 2 D 6$, while the lower estimates are possibly caused by a variety of factors including inconsistencies in inclusion criteria, genotyping comprehensiveness, translation of genotype to phenotype, adjustment for other clinical variables, and differences in the endoxifen measurement assays. The following section will review six factors that may have influenced the CYP2D6-endoxifen relationship, which also likely contribute to the inconsistent results from studies investigating the association of CYP2D6 genotype or endoxifen concentration with tamoxifen treatment efficacy [66]. 
Table 3. Overview of studies reporting CYP2D6 genotypes in correlation with endoxifen concentrations.

\begin{tabular}{|c|c|c|c|c|c|c|c|c|c|}
\hline \multirow[b]{2}{*}{$\mathbf{n}$} & \multicolumn{2}{|c|}{ Patients } & \multicolumn{2}{|c|}{ CYP2D6 Genotype and Phenotype Scoring } & \multirow{2}{*}{$\begin{array}{c}\begin{array}{c}\text { Endox } \\
\text { Assay }\end{array} \\
\text { Z/Total } \\
\end{array}$} & \multicolumn{3}{|c|}{$\begin{array}{c}\text { \% Endox or Metabolic Ratio (MR) Explained } \mathrm{r}^{2} \text {, } \\
\text { (Adjusted. } \mathrm{r}^{2} \text { ) }\end{array}$} & \multirow{2}{*}{$\begin{array}{r}\text { Study } \\
\text { Ref } \\
\end{array}$} \\
\hline & Race & Exclusion Criteria & CYP2D6 * Alleles & Scoring & & Endox & MR & Covariates & \\
\hline 236 & Caucasian & Tam $<10 \%$ mean & $3,4,5,6,7,9,10,41, \mathrm{CNV}$ & DT & Sqrt-z & 38.6 & 68 & None & [28] \\
\hline 583 & Mixed & Tam<150 nM, inhibitors & $3,4,5,6,9,10,14,15,17,41, \mathrm{CNV}$ & AS & Log-z & $33-38$ & 53 & $\begin{array}{l}\text { Age, BMI, non-2D6 } \\
\text { genetics }\end{array}$ & [5] \\
\hline 196 & Caucasian & Unspecified tam cut-off & $3,4,5,9,10,41, \mathrm{CNV}$ & DTs & Log-z & $30.1(46)$ & - & $\begin{array}{l}\text { Age, BMI, genetics, } \\
\text { inhibitors, season }\end{array}$ & [67] \\
\hline 97 & Caucasian & None & $2,3,4,5,6,7,8,9,10,11,15,17,29,35,41, \mathrm{CNV}$ & MG\# & Total & $(26)$ & $(38)$ & Age, ethnicity & [69] \\
\hline 80 & Caucasian & None & $4,6,8$ & DTs & Total & 23 & - & None & [3] \\
\hline 1370 & Caucasian & None & CYP450 AmpliChip, CNV & MG & Z & $18(46)$ & - & $\begin{array}{l}\text { Age, BMI, race, tam } \\
\text { conc }\end{array}$ & [4] \\
\hline 730 & European & Tam<LLQ & $4,9,10,7,6,17,41, \mathrm{CNV}$ & DTs & Z & $16.8(19.4)$ & - & $\begin{array}{c}\text { Inhibitors, non-2D6 } \\
\text { genetics }\end{array}$ & [70] \\
\hline 178 & Caucasian & Inhibitors, non-adherence & $2,3,4,5,6,7,8,9,10,11,15,17,29,35,41, \mathrm{CNV}$ & MG \# & Z & (16) & - & $\begin{array}{c}\text { CYP3A4, } \\
\text { demographics }\end{array}$ & [71] \\
\hline 224 & Asian & $\begin{array}{l}\text { Unspecified tam cut off, } \\
\text { inhibitors }\end{array}$ & $2,3,4,5,6,10,41$ & MG & Total & 10 & - & None & [41] \\
\hline 116 & Caucasian & None & $\begin{array}{c}2,2 \mathrm{~A}, 3,4,5,6,7,8,9,10,11,12,14,17,29,35 \\
41, \mathrm{CNV}\end{array}$ & AS & Total & - & $29.6(33.7)$ & Inhibitors & [73] \\
\hline 83 & Caucasian & Endoxifen $<$ LLQ & $2,2 \mathrm{~A}, 3,4,5,6,7,8,9,10,12,14,17,29,41, \mathrm{CNV}$ & MG & Z & - & - & None & [40] \\
\hline 202 & Asian & Inhibitors or inducers & $2,5,10, \mathrm{CNV}$ & DTs * & Z & - & - & None & [74] \\
\hline 122 & Caucasian & Tam $<150 \mathrm{nM}$ & $2,3,4,5,6,7,8,14,9,10,18,41,14 \mathrm{~B}, \mathrm{CNV}$ & MG & Z & & & None & [75] \\
\hline 77 & Caucasian & Inhibitors, non-adherence & $2,2 \mathrm{~A}, 3,4,5,6,7,8,9,10,11,12,17,41, \mathrm{CNV}$ & AS & Z & - & - & None & [76] \\
\hline 98 & Asian & SSRIs & $5,10,21,41$ & DTs & $Z$ & - & - & None & [77] \\
\hline 117 & Caucasian & Inhibitors & CYP450 AmpliChip, CNV & MG & Total & - & - & None & [78] \\
\hline 119 & Mixed & None & $2,2 \mathrm{~A}, 3,4,5,6,7,8,9,10,11,12,17, \mathrm{CNV}$ & AS & Log-z & - & - & Inhibitors & [32] \\
\hline
\end{tabular}


Table 3. Cont.

\begin{tabular}{|c|c|c|c|c|c|c|c|c|c|}
\hline \multicolumn{3}{|c|}{ Patients } & \multicolumn{2}{|c|}{ CYP2D6 Genotype and Phenotype Scoring } & \multirow{2}{*}{$\begin{array}{c}\begin{array}{c}\text { Endox } \\
\text { Assay }\end{array} \\
\text { Z/Total } \\
\end{array}$} & \multicolumn{3}{|c|}{$\begin{array}{c}\text { \% Endox or Metabolic Ratio (MR) Explained } \mathbf{r}^{2} \text {, } \\
\text { (Adjusted. } \mathbf{r}^{2} \text { ) }\end{array}$} & \multirow{2}{*}{$\begin{array}{r}\text { Study } \\
\text { Ref } \\
\end{array}$} \\
\hline n & Race & Exclusion Criteria & CYP2D6 * Alleles & Scoring & & Endox & MR & Covariates & \\
\hline 35 & Mixed & Inhibitors & $2,3,4,9,10,17,29,35,41$ & AS & Total & - & - & $\begin{array}{l}\text { Race, menopausal } \\
\text { status }\end{array}$ & [79] \\
\hline 667 & Caucasian & None & CYP450 AmpliChip, CNV & $\mathrm{MG}^{*}$ & $\mathrm{Z}$ & - & - & None & [42] \\
\hline 80 & Asian & None & $2,5,6,10,39,41, \mathrm{CNV}$ & AS & Total & - & - & $\begin{array}{l}\text { Tam conc., BMI, } \\
\text { non-2D6 genetics }\end{array}$ & [80] \\
\hline 152 & Caucasian & Unspecified tam cut-off & $2,3,4,5,6, \mathrm{CNV}$ & $\mathrm{MG}^{*}$ & Total & - & - & Age & [65] \\
\hline 120 & Caucasian & None & CYP450 AmpliChip, CNV & DTs/MG & Total & - & - & Inhibitors & [82] \\
\hline 114 & Caucasian & None & $3,4,5,6,9,41$ & AS/MG & $\mathrm{Z}$ & - & - & None & [83] \\
\hline 183 & Asian & Inhibitors & $2,4,6,10,14,18,21,36,41,44, \mathrm{CNV}$ & DT & $\mathrm{Z}$ & - & - & None & [46] \\
\hline 42 & Native American & None & $2,3,4,5,9,10,28,33,35,41$ & AS/DTs & Total & - & - & $\begin{array}{l}\text { Age, site, non-2D6 } \\
\text { genetics }\end{array}$ & [84] \\
\hline 158 & Caucasian & None & CYP450 AmpliChip, CNV & DTs & Total & - & - & Inhibitors & [19] \\
\hline
\end{tabular}

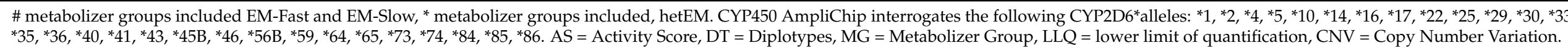




\subsubsection{CYP2D6 Genotyping Comprehensiveness}

Insufficient comprehensiveness in determining CYP2D6 * alleles and CNVs contribute to inaccurate prediction of CYP2D6 metabolic activity as demonstrated in a study re-genotyping 492 breast cancer patients using Roche's CYP450 AmpliChip assay that demonstrated significantly improved stratification of patients into activity groups and reduced misclassifications [85]. Endoxifen concentrations were not measured in the population, but the results indicate that more comprehensive genotyping would allow for greater detection of the pharmacogenetic association. The first studies to report on the CYP2D6-endoxifen association interrogated only a handful of no-function alleles thereby misclassifying patients as wild-type/normal metabolizers. Only one of these studies [3] reported an $\mathrm{r}^{2}$ value $(23 \%)$. Out of the 30 studies presented in Table 3, only 6 studies were genotyped using the Roche's CYP450 Amplichip assay which interrogates 33 distinct CYP2D6 * alleles and is considered the gold standard in CYP2D6 genotyping. Surprisingly, the two studies that reported $\mathrm{r}^{2} \mathrm{~s}$ and were genotyped with Amplichip were among the bottom 5 studies in terms of $\mathrm{r}^{2}$ estimates. There was no clear trend in terms of genotyping comprehensiveness and $\mathrm{r}^{2}$ estimates. However, most of the studies $(21 / 30)$ had determined 7 or more different CYP2D6 * alleles, which covers the most common CYP2D6 variants including intermediate function alleles. Most studies (19/30) also determined copy number variations $(\mathrm{CNVs})$ and were thus able to identify ultra-rapid metabolizers which increased the accuracy of genotype to phenotypic activity prediction [86]. Determination of CNVs may be of equal importance as detection of rare alleles by the AmpliChip assay.

\subsubsection{CYP2D6 Activity Phenotype Scoring}

Use of different systems to translate CYP2D6 genotype to phenotype has led to inconsistencies in metabolic activity phenotype assignments between laboratories and investigators and introduces an additional challenge in comparing results between studies [87]. Prior to the implementation of the consensus scoring system [63], the functional activity diplotypes (i.e., IM/EM) were frequently used as the phenotype or further combined into metabolic activity phenotype groups (i.e., UM, EM, IM, PM). Alternatively, some studies used the Activity Score (AS) system [88], which assigns each allele an activity score and sums the allele scores into one activity score that may be used a continuous variable or categorized into metabolizer groups.

At least three different scoring methods (metabolizer groups, diplotypes and the activity score) were utilized in the 30 studies presented in Table 3 and the scoring methods used was relatively evenly distributed between the studies (11, 8 and 9 respectively). Of the 11 studies that reported an $\mathrm{r}^{2}$ estimate six utilized diplotypes to score CYP2D6 activity and reported unadjusted $\mathrm{r}^{2}$ s between $15 \%$ and $38 \%$. Among these studies there were also variations within the same scoring methods, such as recoding UM alleles to NM alleles [72]. The previous version of the AS score [88] was utilized by two studies, one of which [5] reported $\mathrm{r}^{2}$ estimates of 33-38\% within 3 ethnic subgroups. The second study [73] did not report an $\mathrm{r}^{2}$ estimate for endoxifen but reported that $30 \%$ of the variability in the metabolic ratio between endoxifen and NDtam was explained by CYP2D6 genotype. It should be noted that analyses of metabolic ratio usually produce higher $\mathrm{r}^{2}$ estimates as it more directly reflects the conversion of NDtam to endoxifen. The three studies that categorized patients into metabolizer groups reported unadjusted $\mathrm{r}^{2}$ estimates of $10 \%, 18 \%$, and $26 \%$, though that final estimate was adjusted for clinical variables including age and race.

\subsubsection{Racial Differences in CYP2D6 Allele Frequencies}

Another factor that may impair the prediction of endoxifen by CYP2D6 is not accounting for the differences in frequencies of $C Y P 2 D 6$ genetic variations among racial groups [62]. For example, the reduced activity CYP2D $6^{*} 10$ allele is carried by $\sim 40 \%$ of Asian individuals but $<6 \%$ of Africans and Europeans. Conversely, CYP2D $6 * 17$ is found in $\sim 22 \%$ of African Americans and $<1 \%$ of Asians and Europeans [62]. It is therefore reasonable to assume that more comprehensive genotyping is of greater importance in cohorts with large racial 
diversity. Similar to most pharmacogenetics research, these studies primarily included Caucasian patients (19/30) with the remaining studies including, six Asian cohort, three mixed cohorts and a Native American/Alaskan cohort. The Asian study reported the lowest $\mathrm{r}^{2}$ among the cohorts that provided endoxifen estimates. As mentioned earlier, CYP2D $6^{*} 10$ is common in Asian patients with an allele frequency of $52 \%$ and has been shown to reduce endoxifen levels in Asian patients to a similar degree as non-functional alleles $[74,89,90]$. The recent consensus system updated the scoring of CYP2D $6^{*} 10$ from 0.5 to 0.25 [63], which may have improved the predictive performance of CYP2D6 genetics [87]. An analysis of 20 breast cancer cohorts using tamoxifen indicated that rescoring the CYP2D $6^{*} 10$ allele to an activity of 0.25 increased the prediction of endoxifen in Asian cohorts and to a lesser extent in Caucasians [91]. The study by Saladores et al. reported separate $r^{2} s$ for the different ethnic groups in which the Asian cohort accrued in Singapore produced the largest $\mathrm{r}^{2}$ estimate. The lowest estimate (33\%) was found in the cohort collected in the UK, which might indicate greater racial diversity.

\subsection{Concomitant Use of CYP2D6 Inhibitors}

Unlike the external sources of endoxifen variability such as genotyping comprehensiveness and adherence, CYP2D6 inhibitor use is a legitimate source of biological variability as concomitant drugs reduce CYP2D6 activity via phenoconversion [2,3]. Inclusion of patients using potent CYP2D6 inhibitors increases misclassification and thereby reduces accuracy of endoxifen prediction. Studies investigating the CYP2D6-predicted endoxifen-outcome association should therefore always account for potent CYP2D6 inhibitor use. This may be less important for the use of weak CYP2D6 inhibitors as they have not been consistently shown to significantly impact endoxifen levels as recently reviewed elsewhere [8].

A reasonable assumption would be that removal of strong inhibitor-users would increase the predictive power of CYP2D6. Inhibitor users were excluded from 11 of the 30 studies and from 3 of the studies reporting $\mathrm{r}^{2}$ estimates in Table 3 and these studies were randomly distributed across the table ranked according to $\mathrm{R}$ square estimates. However, several datasets used inhibitor data as an adjustment variable, which contributed to increased prediction of endoxifen levels together with CYP2D6. Due to current guidelines for these well-established drug interactions [50], patients recruited to recent studies are less likely to have been co-prescribed strong CYP2D6 inhibitors, though a large cohort analysis indicates the efficacy reduction from CYP2D6 inhibitors may be limited [92].

\subsection{Tamoxifen Adherence}

The results in Table 3 originate from studies that include patients at steady state and due to tamoxifen's long half-life there is little variation expected to occur throughout the day and in terms of timing of dosing. However, a major external source of endoxifen variability is adherence to the drug [93-95] which reduce the association between CYP2D6 and endoxifen concentrations and is thus an obvious factor that should be accounted for when associating CYP2D6 to clinical outcomes. The 30 studies summarized in Table 3 have applied distinct approaches for excluding non-adherent patients including the more classic approaches of self-reported compliance and pill-counts to using various pharmacokinetic cut offs based on tamoxifen concentrations. The tamoxifen cut offs ranged from excluding patients under the lower limit of tamoxifen quantification [70], removing patients with tamoxifen levels less than $10 \%$ of the mean [68] or by identification and removal of patients with deviating tamoxifen levels based on splits in the tamoxifen concentration distribution [5]. In addition, some studies used tamoxifen concentrations as an adjustment variable along with CYP2D6 and/or other factors to predict endoxifen. This approach may be questionable as tamoxifen concentrations are linearly related to endoxifen, thereby inflating the estimates [3]. All these approaches sought to identify and remove patients with poor tamoxifen adherence. The three studies with relatively strict pharmacokinetic adherence cut offs ( $10 \%$ of the mean $/ 150 \mathrm{nM}$ tamoxifen) all reported high $\mathrm{r}^{2} \mathrm{~s}$ ranging from $27 \%$ to $38 \%$. However, a study in an independent cohort found moderate correlation between 
the $150 \mathrm{nM}$ adherence cut off and patient-reported non-adherence [93]. This indicates that low tamoxifen concentrations may also be pharmacology-related, perhaps via reduced absorption or increased first-pass metabolism, and that removal of such patients may artificially inflate the estimated contribution of CYP2D6 activity to endoxifen generation.

\subsection{Endoxifen Measurement}

Endoxifen may exist as different isomers (Z, E, Z-4-prime) [28] for which Z-endoxifen is the main active metabolite generated by CYP2D6. Selective LC-MS/MS methods are necessary to differentiate these isomers and avoid inaccurate Z-endoxifen measurement [96] which may obscure identification or verification of endoxifen predictors that may be important contributors in a possible prediction algorithm. Approximately half of the datasets (16/30) in Table 3 measured Z-endoxifen while the remaining studies did not separate the Z, Z-4-prime and E isomers. Of note, four of the top five studies in terms of explained endoxifen variability were all performed using z-isomer assays, while the study with the lowest explained variability was performed using total-endoxifen. This excludes the study that only reported an estimate based on metabolic ratio [73]. In addition, there were discrepancies among the studies in terms of using log formatted endoxifen concentrations in the regression analyses when obtaining the $\mathrm{R}$ squared values. Of note, most of the studies producing the highest $\mathrm{r}^{2}$ estimates used log or square root transformed endoxifen concentrations whereas most of the studies that did not transform the data had lower estimates.

\subsection{Other Clinical Variables Associated with Endoxifen Concentrations}

Several non-pharmacogenetic patient factors have been associated with steady state endoxifen concentrations including age, BMI, adherence, gender, and season and addition of clinical factors to multivariable regression models have been reported to predict endoxifen concentrations more accurately than by using CYP2D6 as a single predictor $[67,72]$. These factors and their associations to tamoxifen and metabolite concentrations have recently been extensively reviewed elsewhere [8]. Briefly, increasing age has been positively associated with endoxifen and 4OHtam concentrations [97,98]. An inverse relationship is seen with BMI, in which high BMI is predictive of lower tamoxifen and metabolite levels [72,97]. There are also reports suggesting lower endoxifen concentrations during winter compared to other seasons [67,72], However, there are conflicting data regarding this putative association [8]. Clinical predictors of endoxifen concentration have been discovered in small patient cohorts, increasing risk of false positives and negatives. Therefore, definitive investigation of the contribution of these factors should be re-analyzed in a pooled analysis of datasets that collected variables that have been reported to contribute to variability in endoxifen concentrations.

\subsection{Effect of CYP2D6 Genetic Variation on Other Active Metabolites}

$4 \mathrm{OHtam}$ has similar ER affinity as endoxifen and its concentrations may also contribute to tamoxifen efficacy, as previously reviewed. In addition to its role in endoxifen formation, CYP2D6 is involved in the metabolic conversion of tamoxifen to $4 \mathrm{OHtam}$ (Figure 2). CYP2D6 genotype has been estimated to explain approximately $9 \%$ of the variability in $4 \mathrm{OHtam}$ concentrations [28] and $27.6 \%$ of the variability in the metabolic ratio (tamoxifen/4OHtam) [28]. There are multiple reports of increasing 4OHtam concentrations as CYP2D6 metabolizer activity phenotype increases [68,73,89,99,100], as well as increasing activity scores [84]. Studies focusing solely on the diminished activity CYP2D $6^{*} 10$ allele commonly found among Asians have reported lower 4OHtam concentrations for homozygous carriers of this variant compared to wild type patients [74,101]. Similar to endoxifen, the explanation of variability from CYP2D6 is even greater when analyzing the metabolic ratio (tamoxifen/4OHtam) [70,80,84]. Although CYP2D6 genotype is an important factor in determining $4 \mathrm{OHtam}$ concentrations, this association appears to be somewhat weaker 
than the relationship with endoxifen $[32,41,82,102]$ and likely has a minimal contribution to the putative CYP2D6-efficacy relationship.

\section{Contribution of Other Enzymes to Tamoxifen Metabolite Concentrations}

CYP2D6 metabolic activity explains at most approximately $50 \%$ of the variability in endoxifen concentrations. Validating the endoxifen-outcome association will likely require a precise endoxifen prediction algorithm that includes other variables that contribute to endoxifen concentrations. As illustrated in Figure 2, there are many enzymes involved in tamoxifen metabolism including CYP2Cs, CYP3As, SULTs, and UGTs. The following sections will summarize the reported associations for genetic variants in these enzymes with concentrations of tamoxifen, endoxifen, and other metabolites. While some of these associations have been consistently found across studies, as described below, some have only been detected in a single study and require further replication. Several studies have investigated associations for functionally consequential variants within other genes not described below, including CYP2B, flavin mono-oxygenase (FMO), and the P-glycoprotein / ABCB1 transporter; however, there is a lack of evidence of association for variation within these genes with concentrations of tamoxifen or of its metabolites [28].

\subsection{CYP2Cs}

CYP2Cs, including CYP2C8, CYP2C9, and CYP2C19, contribute to the metabolism of many xenobiotic compounds [103]. CYP2Cs contribute to the conversion of tamoxifen to $\mathrm{Z}-4-\mathrm{OH} t a m$ and CYP2C19 is also involved in the conversion of Z-4-OHtam to endoxifen, as illustrated in Figure $2[28,72,104]$. Compared with CYP2D6, the contribution of CYP2Cs to endoxifen generation is relatively small, explaining less than 3\% [5].

CYP2C9*2 (rs1799853; MAF $=0.119)$ and CYP2C9*3 (rs1057910; MAF $=0.069)$ are common, diminished activity $C Y P 2 C 9$ variant alleles. In human liver microsomes metabolism of tamoxifen to $4 \mathrm{OH}$ tam is decreased in CYP2C9*2 and CYP2C9*3 samples by $48 \%$ and $89 \%$, respectively [105], which is similar to the effect of incubation with a CYP2C9 inhibitor [105]. Multiple studies have found that carriers of these reduced activity alleles have lower concentrations of active tamoxifen metabolites including endoxifen and 4OHtam (Table 4) [28].

CYP2C19 polymorphisms have also been investigated for their effect on tamoxifen metabolism. CYP2C19 has two common null activity alleles, CYP2C19*2 (rs4244285; $\mathrm{MAF}=0.148)$ and $C Y P 2 C 19 * 3(\mathrm{rs} 4986893 ; \mathrm{MAF}=0.012)$ [106] and one common enhanced activity allele CYP2C19*17 (rs12248560; MAF $=0.225)$ [99]. Clinical studies have reported that patients with higher CYP2C19 metabolic activity phenotype have higher conversion of tamoxifen to its active metabolites, particularly $4 \mathrm{OHtam}[73,99]$.

CYP2C8 is another polymorphic enzyme within this CYP enzyme family. Out of the fourteen identified CYP2C 8 variant alleles, CYP2C $8 * 2(\mathrm{rs} 11572103, \mathrm{MAF}=0.012), C Y P 2 C 8^{*} 3$ $(\mathrm{rs} 11572080 ; \mathrm{MAF}=0.105)$, and $C Y P 2 C 8^{*} 4(\mathrm{rs} 1058930 ; \mathrm{MAF}=0.04)$ are relatively common diminished activity variants $[107,108]$. CYP2C $8^{*} 2$ is the most common in African American population, whereas CYP2C $8^{*} 3$ is the most common in Caucasian populations $[107,108]$. One study reported univariate associations of CYP2C8 activity phenotype with endoxifen; however, this association was attributed to linkage between $C Y P 2 C 8$ and $C Y P 2 C 9$ [72].

\subsection{CYP3As}

CYP3A, including CYP3A4 and CYP3A5, are highly active in drug metabolism [103]. CYP3A4 and CYP3A5 participate in the conversions of tamoxifen to NDtam and of 4OHtam to endoxifen [67]. Similar to CYP2D6, CYP3A4 has several known polymorphisms that affect enzyme activity. One of the most well-established functionally consequential variants is CYP3A4*22 (intron 6 C > T; rs35599367) [109], which reduces CYP3A4 gene expression and enzyme activity approximately 2-fold in in vitro studies of human liver samples [110]. In clinical studies, plasma concentrations of endoxifen in CYP3A4*22 carriers were up to 1.4-fold greater than wildtype patients, and carriers also had higher concentrations of tamoxifen, NDtam, and 4OHtam [67]. This increase in endoxifen concentrations is 
unexpected for a reduced activity polymorphism. It is hypothesized that patients carrying CYP3A4*22 have higher levels of tamoxifen and all of its metabolites due to reduced intestinal CYP3A activity and first-pass metabolism, which would increase tamoxifen bioavailability [67]. Other studies have not reported a difference in concentrations of tamoxifen or its metabolites in CYP3A4*22 carriers [71,84,111,112]

Other CYP3A4 variants, such as CYP3A4*1B (rs2740574; A > G) and CYP3A4*18 (rs28371759; T > C), have not been extensively studied in tamoxifen bioactivation, partially due to inadequate allele frequency $[73,113]$. Moreover, CYP3A4*20 (rs67666821), CYP3A4*6, CYP3A4*26 alleles have previously been identified as loss-of-function alleles but their polymorphic effects in tamoxifen bioconversion and treatment effectiveness have not been examined [114].

The contribution of genetic variants in CYP3A5 to endoxifen has also been studied. CYP3A5*3 (rs776746) is a loss of function allele that is more common in African Americans $(\mathrm{MAF}=0.13)$ than Caucasians $(\mathrm{MAF}=0.01)$ [115]. Clinical studies have not reported any effect of $C Y P 3 A 5^{*} 3$ on endoxifen levels [84,90,112,113,115-117], even in large studies that conducted subgroup analyses stratified by CYP2D6 and CYP2C9/19 phenotype [73].

\subsection{SULTS}

Sulfotransferases (SULTs) are phase II liver enzymes that catalyze sulfation of endogenous and exogenous compounds, thereby increasing the water solubility for excretion. There are 12 main SULTS, with SULT1A1 and SULT1A2 the most commonly expressed and studied isoforms [118]. SULT1A1 metabolizes the tamoxifen metabolites $4 \mathrm{OHtam}$ and endoxifen into $4 \mathrm{OHtam}$ sulfate and endoxifen sulfate, respectively [119]. SULT1A1 is a highly polymorphic gene among different ethnicities [120]. Carriers of two variants in SULT1A1 (rs6839, rs1042157) have been reported to have 10-15\% higher levels of endoxifen and $4 \mathrm{OH}$ tam. Similarly, the most common variants of SULT1A2 are SULT1A2*2 (rsID27742, MAF $=0.00273$ ), which is found in LD with SULT1A1*2 [121], and SULT1A2*3 (rs762632, MAF $=0.104)$ [119]. Patients carrying these SULT1A2 variants also have higher endoxifen and 4OHtam metabolite levels [82]. However, in the same study SULT1A1 genotypes did not demonstrate any associations between tamoxifen and its metabolites.

\subsection{UGTS}

UDP-glucuronosyltransferase (UGTs) are another group of phase II metabolic enzymes that prepare compounds for elimination by adding a glucuronide group. UGTs have been demonstrated to be involved in the phase II metabolism of tamoxifen and its metabolites. There are several commonly studied polymorphic UGT enzymes including UGT1A4, UGT2B7, and UGT2B15, and their role in the metabolism of tamoxifen has been previously reviewed in detail [122-124]. UGT1A4 contributes to the N-glucuronidation of tamoxifen and 4OHtam [122]. Multiple studies have reported that patients carrying the UGT1A4 Leu48Val variant have higher concentrations of tamoxifen-N-glucuronide $[28,123]$ and lower concentrations of other glucuronidated metabolites [125]. UGT2B7 is responsible for glucuronidation of endoxifen. UGT2B7 is highly polymorphic, and UGT2B $7^{*} 2$ (His268Tyr, rs24648760) has reduced in vitro glucuronidation activity [125]. Patients carrying $U G T 2 B 7^{*} 2$ have been found to have higher concentrations of tamoxifen and endoxifen, and lower concentrations of glucuronidated metabolites [81,125]. Finally, Romero Lorca et al. reported that patients carrying UGT2B15 Lys523Thr or UGT2B17 deletion have higher concentrations of certain glucuronidated metabolites [125], though these unexpected findings require independent validation. 
Table 4. Non-CYP2D6 Enzymes associated with tamoxifen, endoxifen, or other metabolites.

\begin{tabular}{|c|c|c|c|c|}
\hline Gene & Variants & Metabolites Measured & Reported Association & Ref. \\
\hline \multirow{4}{*}{ CYP2C9 } & $* 2$ and $* 3$ & $\begin{array}{l}\text { Tam, 4OHtam, endoxifen, } \\
\text { glucuronides, E and Z }\end{array}$ & Lower $4 \mathrm{OHtam}$ and endoxifen & [28] \\
\hline & $* 2$ and $* 3$ & $\begin{array}{l}\text { Tam, NDtam, } 4 \text { OHtam, } \\
\text { endoxifen, N,N-DDtam, } \\
\text { norendoxifen }\end{array}$ & Lower $4 \mathrm{OHtam} /$ tam ratio & [5] \\
\hline & *1-*11 & Endoxifen & $\begin{array}{l}\text { Lower endoxifen and end } / 4 \mathrm{OHtam} \\
\text { ratio }\end{array}$ & [73] \\
\hline & $* 2$ and $* 3$ & Endoxifen & Lower endoxifen & [72] \\
\hline \multirow{4}{*}{ CYP2C19 } & *2 & $\begin{array}{l}\text { Tamoxifen, NDtam, tamNoX, } \\
\text { Z-4'-OH-Tam, Z-4OH-tam, } \\
\text { Z-endoxifen, Z-4'-endoxifen }\end{array}$ & Higher Tam/4OHtam ratio & [70] \\
\hline & $* 2, * 3, * 17$ & Endoxifen & Higher 4OHtam & [73] \\
\hline & $* 2, * 3, * 17$ & $\begin{array}{l}\text { Tam, NDtam, 4OHtam, } \\
\text { endoxifen, N,N-DDtam, } \\
\text { norendoxifen }\end{array}$ & $\begin{array}{l}\text { Lower norendoxifen } / \mathrm{N}, \mathrm{N}-\mathrm{DD} \text {-tam } \\
\text { ratio }\end{array}$ & [5] \\
\hline & $* 2, * 3, * 17$ & Tam, 4OHtam, NDtam & Higher $4 \mathrm{OHtam} /$ tam ratio & [99] \\
\hline \multirow[b]{2}{*}{ CYP3A4 } & *22 & Endoxifen & Higher endoxifen & [67] \\
\hline & $* 22$ & $\begin{array}{l}\text { Tamoxifen, NDtam, tamNoX, } \\
\text { Z-4'-OHtam, Z-4-OH-tam, } \\
\text { Z-endoxifen, Z-4'-endoxifen }\end{array}$ & Higher endoxifen & [70] \\
\hline SULT1A1 & rs6839, rs1042157 & $\begin{array}{l}\text { Tamoxifen, endoxifen, 4OHtam } \\
\text { and NDtam }\end{array}$ & Higher endoxifen and $4 \mathrm{OHtam}$ & [119] \\
\hline SULT1A2 & $* 2$ and $* 3$ & $\begin{array}{l}\text { Tam, 4OHtam, NDtam, } \\
\text { endoxifen, TamNoX }\end{array}$ & Higher endoxifen and $4 \mathrm{OH}$-tam & [82] \\
\hline \multirow{3}{*}{ UGT1A4 } & Leu48Val & $\begin{array}{l}\text { Tam, } 4 \text { OHtam, endoxifen, } \\
\text { glucuronides, E and Z }\end{array}$ & Lower tam/Tam-N-glucoronide ratio & [28] \\
\hline & Leu48Val & $\begin{array}{l}\text { Glucuronidated metabolites of } \\
\text { endoxifen and } 4 \mathrm{OH} \text { tam }\end{array}$ & $\begin{array}{l}\text { Lower } 4 \text { OHtam-N-Gluc and } \\
\text { endoxifen-gluc }\end{array}$ & [125] \\
\hline & Leu48Val & $\begin{array}{l}\text { Tamoxifen, E and Z-endoxifen, E- } \\
\text { and Z-4-OHtam and the } \\
\text { corresponding glucuronides }\end{array}$ & Higher Tam-N-gluc & [123] \\
\hline \multirow[b]{2}{*}{ UGT2B7 } & *2 (His268Tyr) & Tam and endoxifen & Higher endoxifen & [81] \\
\hline & *2 (His268Tyr) & $\begin{array}{l}\text { Glucuronidated metabolites of } \\
\text { endoxifen and } 4 \mathrm{OH} \text { tam }\end{array}$ & $\begin{array}{c}\text { Higher Tam, 4OHtam, NDtam. Lower } \\
\text { 4OHtam-O-gluc and } \\
\text { 4-OH-Tam-N-gluc }\end{array}$ & [125] \\
\hline UGT2B15 & Lys523Thr & $\begin{array}{l}\text { Glucuronidated metabolites of } \\
\text { endoxifen and } 4 \mathrm{OHtam}\end{array}$ & $\begin{array}{l}\text { Higher 4-OH-Tam-O-gluc and } \\
\text { endoxifen-gluc }\end{array}$ & [125] \\
\hline UGT2B17 & Deletion & $\begin{array}{l}\text { Glucuronidated metabolites of } \\
\text { endoxifen and } 4 \mathrm{OH} \text { tam }\end{array}$ & Higher 4OHtam-N-gluc & [125] \\
\hline
\end{tabular}

\section{Conclusions and Directions for Future Research}

Building a precise endoxifen prediction algorithm requires integrating the genetic and clinical variables discussed above. Several approaches to building an integrated algorithm have been reported including using standard linear regression [67]. In recent years pharmacokinetic modeling approaches have been used to investigate the factors contributing to metabolite concentrations $[94,97,126-128]$. These studies generally identified the same important factors but provide more mechanistic understanding of their effects on endoxifen concentration variability $[97,127,128]$ and could be more precisely adapted into personalized dosing algorithms to achieve target endoxifen concentrations [94]. Finally, 
novel machine learning techniques have been utilized to improve model precision, though translation of these models into clinical practice may be challenging [129].

The possibility that there are patients who receive diminished clinical benefit from tamoxifen treatment due to metabolic resistance has been heavily debated over the last two decades. Recent prospective trials investigating metabolic resistance have been negative both by using CYP2D6 as a predictor of endoxifen steady state concentrations and by using endoxifen concentrations directly [42]. However, these prospective studies have premature follow-up data and or have been conducted in the non-adjuvant settings [45,46]. An alternative approach to validate the endoxifen-efficacy association would be to use existing data from large, prospective trials of adjuvant tamoxifen use to predict individual patient's expected endoxifen concentration and test the association with long-term survival data. This strategy would be a vast improvement over previous attempts to use only CYP2D6 genotype that have failed to validate the association $[54,55]$. In this review we have provided evidence-based recommendations on how best to conduct analyses to determine the contribution of CYP2D6 and other genetic and clinical variables to endoxifen concentration. Comprehensive CYP2D6 genotyping, the use of updated standardized scoring of phenotypic activity and endoxifen assays that selectively measures Z-endoxifen are all factors that would allow for increased accuracy in endoxifen prediction. Awareness and removal of non-adherent patients will also allow for removal of external variability that is not attributed to CYP2D6 metabolic activity. The use of potent CYP2D6 inhibitors should also be accounted for to avoid inaccurate prediction caused by phenoconversion. We have also shown that other genetic and clinical factors contribute significantly to variability in endoxifen concentrations and the collection and adjustment for these variables increase the ability to predict endoxifen concentrations in patients with breast cancer.

To move this field forward and to validate the existence of metabolic resistance we firstly suggest generating a precision endoxifen prediction algorithm that properly accounts for all the factors that reduce the accuracy of predicting endoxifen from CYP2D6 genotype and then to integrate other factors genetic and clinical factors that affect endoxifen concentrations. A precision endoxifen algorithm could then be used to re-analyze prospective tamoxifen trials that have long-term follow up data to validate the effect of metabolic resistance and identify the endoxifen threshold below which efficacy is compromised. If successful, this algorithm can further be used to select an appropriate tamoxifen starting dose to achieve target endoxifen concentrations to avoid under-treatment and improve treatment outcomes.

Author Contributions: Conceptualization, D.L.H. and T.H.; data curation, T.H.; writing-original draft preparation, T.H., S.A., C.L.; writing-review and editing, D.L.H., T.H.; visualization, T.H., D.L.H.; supervision, D.L.H.; project administration, D.L.H.; funding acquisition, H.S., G.M. All authors have read and agreed to the published version of the manuscript.

Funding: This work was funded by the Western Norwegian Health Authority Grant number: F-10450 and the U.S.- Norway Fulbright Foundation.

Institutional Review Board Statement: Not applicable.

Informed Consent Statement: Not applicable.

Conflicts of Interest: The authors declare no conflict of interest.

\section{References}

1. Early Breast Cancer Trialists' Collaborative Group (EBCTCG). Effects of chemotherapy and hormonal therapy for early breast cancer on recurrence and 15-year survival: An overview of the randomised trials. Lancet 2005, 365, 1687-1717. [CrossRef]

2. Stearns, V.; Johnson, M.D.; Rae, J.M.; Morocho, A.; Novielli, A.; Bhargava, P.; Hayes, D.F.; Desta, Z.; Flockhart, D.A. Active Tamoxifen Metabolite Plasma Concentrations After Coadministration of Tamoxifen and the Selective Serotonin Reuptake Inhibitor Paroxetine. J. Natl. Cancer Inst. 2003, 95, 1758-1764. [CrossRef]

3. Jin, Y.; Desta, Z.; Stearns, V.; Ward, B.; Ho, H.; Lee, K.H.; Skaar, T.; Storniolo, A.M.; Li, L.; Araba, A.; et al. CYP2D6 genotype, antidepressant use, and tamoxifen metabolism during adjuvant breast cancer treatment. J. Natl. Cancer Inst. 2005, 97, 30-39. [CrossRef] 
4. Madlensky, L.; Natarajan, L.; Tchu, S.; Pu, M.; Mortimer, J.; Flatt, S.W.; Nikoloff, D.M.; Hillman, G.; Fontecha, M.R.; Lawrence, H.J.; et al. Tamoxifen Metabolite Concentrations, CYP2D6 Genotype, and Breast Cancer Outcomes. Clin. Pharmacol. Ther. 2011, 89, 718-725. [CrossRef]

5. Saladores, P.; Murdter, T.; Eccles, D.; Chowbay, B.; Zgheib, N.K.; Winter, S.; Ganchev, B.; Eccles, B.; Gerty, S.; Tfayli, A.; et al. Tamoxifen metabolism predicts drug concentrations and outcome in premenopausal patients with early breast cancer. Pharm. J. 2015, 15, 84-94. [CrossRef] [PubMed]

6. Helland, T.; Naume, B.; Hustad, S.; Bifulco, E.; Kvaløy, J.T.; Saetersdal, A.B.; Synnestvedt, M.; Lende, T.H.; Gilje, B.; Mjaaland, I.; et al. Low Z-4OHtam concentrations are associated with adverse clinical outcome among early stage premenopausal breast cancer patients treated with adjuvant tamoxifen. Mol. Oncol. 2020. [CrossRef] [PubMed]

7. Drögemöller, B.I.; Wright, G.E.B.; Shih, J.; Monzon, J.G.; Gelmon, K.A.; Ross, C.J.D.; Amstutz, U.; Carleton, B.C. CYP2D6 as a treatment decision aid for ER-positive non-metastatic breast cancer patients: A systematic review with accompanying clinical practice guidelines. Breast Cancer Res. Treat. 2019, 173, 521-532. [CrossRef] [PubMed]

8. Sanchez-Spitman, A.B.; Swen, J.J.; Dezentje, V.O.; Moes, D.; Gelderblom, H.; Guchelaar, H.J. Clinical pharmacokinetics and pharmacogenetics of tamoxifen and endoxifen. Expert Rev. Clin. Pharm. 2019, 12, 523-536. [CrossRef] [PubMed]

9. Davies, C.; Pan, H.; Godwin, J.; Gray, R.; Arriagada, R.; Raina, V.; Abraham, M.; Alencar, V.H.M.; Badran, A.; Bonfill, X. Long-term effects of continuing adjuvant tamoxifen to 10 years versus stopping at 5 years after diagnosis of oestrogen receptor-positive breast cancer: ATLAS, a randomised trial. Lancet 2013, 381, 805-816. [CrossRef]

10. Cuzick, J.; Sestak, I.; Bonanni, B.; Costantino, J.P.; Cummings, S.; DeCensi, A.; Dowsett, M.; Forbes, J.F.; Ford, L.; LaCroix, A.Z.; et al. Selective oestrogen receptor modulators in prevention of breast cancer: An updated meta-analysis of individual participant data. Lancet 2013, 381, 1827-1834. [CrossRef]

11. DeCensi, A.; Puntoni, M.; Guerrieri-Gonzaga, A.; Caviglia, S.; Avino, F.; Cortesi, L.; Taverniti, C.; Pacquola, M.G.; Falcini, F.; Gulisano, M.; et al. Randomized Placebo Controlled Trial of Low-Dose Tamoxifen to Prevent Local and Contralateral Recurrence in Breast Intraepithelial Neoplasia. J. Clin. Oncol. Off. J. Am. Soc. Clin. Oncol. 2019, 37, 1629-1637. [CrossRef]

12. Manavathi, B.; Dey, O.; Gajulapalli, V.N.R.; Bhatia, R.S.; Bugide, S.; Kumar, R. Derailed Estrogen Signaling and Breast Cancer: An Authentic Couple. Endocr. Rev. 2013, 34, 1-32. [CrossRef] [PubMed]

13. Shiau, A.K.; Barstad, D.; Loria, P.M.; Cheng, L.; Kushner, P.J.; Agard, D.A.; Greene, G.L. The Structural Basis of Estrogen Receptor/Coactivator Recognition and the Antagonism of This Interaction by Tamoxifen. Cell 1998, 95, 927-937. [CrossRef]

14. Brzozowski, A.M.; Pike, A.C.; Dauter, Z.; Hubbard, R.E.; Bonn, T.; Engström, O.; Öhman, L.; Greene, G.L.; Gustafsson, J.-Å.; Carlquist, M. Molecular basis of agonism and antagonism in the oestrogen receptor. Nature 1997, 389, 753. [CrossRef] [PubMed]

15. Jordan, V.C. New insights into the metabolism of tamoxifen and its role in the treatment and prevention of breast cancer. Steroids 2007, 72, 829-842. [CrossRef]

16. Patterson, J.S.; Settatree, R.S.; Adam, H.K.; Kemp, J.V. Serum concentrations of tamoxifen and major metabolite during long-term nolvadex therapy, correlated with clinical response. Eur. J. Cancer 1980, 1 (Suppl. 1), 89-92. [PubMed]

17. Desta, Z.; Ward, B.A.; Soukhova, N.V.; Flockhart, D.A. Comprehensive Evaluation of Tamoxifen Sequential Biotransformation by the Human Cytochrome P450 System in Vitro: Prominent Roles for CYP3A and CYP2D6. J. Pharmacol. Exp. Ther. 2004, 310, 1062-1075. [CrossRef] [PubMed]

18. Klein, D.J.; Thorn, C.F.; Desta, Z.; Flockhart, D.A.; Altman, R.B.; Klein, T.E. PharmGKB summary: Tamoxifen pathway, pharmacokinetics. Pharm. Genom. 2013, 23, 643-647. [CrossRef] [PubMed]

19. Borges, S.; Desta, Z.; Li, L.; Skaar, T.C.; Ward, B.A.; Nguyen, A.; Jin, Y.; Storniolo, A.M.; Nikoloff, D.M.; Wu, L.; et al. Quantitative effect of CYP2D6 genotype and inhibitors on tamoxifen metabolism: Implication for optimization of breast cancer treatment. Clin. Pharmacol. Ther. 2006, 80, 61-74. [CrossRef] [PubMed]

20. Brauch, H.; Jordan, V.C. Targeting of tamoxifen to enhance antitumour action for the treatment and prevention of breast cancer: The 'personalised' approach? Eur. J. Cancer 2009, 45, 2274-2283. [CrossRef]

21. Poon, G.K.; Chui, Y.C.; McCague, R.; Lłnning, P.E.; Feng, R.; Rowlands, M.G.; Jarman, M. Analysis of phase I and phase II metabolites of tamoxifen in breast cancer patients. Drug Metab. Dispos. 1993, 21, 1119-1124.

22. Lu, W.J.; Xu, C.; Pei, Z.; Mayhoub, A.S.; Cushman, M.; Flockhart, D.A. The tamoxifen metabolite norendoxifen is a potent and selective inhibitor of aromatase (CYP19) and a potential lead compound for novel therapeutic agents. Breast Cancer Res. Treat. 2012, 133, 99-109. [CrossRef]

23. Lien, E.A.; Solheim, E.; Kvinnsland, S.; Ueland, P.M. Identification of 4-Hydroxy-N-desmethyltamoxifen as a Metabolite of Tamoxifen in Human Bile. Cancer Res. 1988, 48, 2304. [PubMed]

24. Falany, C.N. Enzymology of human cytosolic sulfotransferases. FASEB J. 1997, 11, 206-216. [CrossRef] [PubMed]

25. Nishiyama, T.; Ogura, K.; Nakano, H.; Ohnuma, T.; Kaku, T.; Hiratsuka, A.; Muro, K.; Watabe, T. Reverse geometrical selectivity in glucuronidation and sulfation of cis- and trans-4-hydroxytamoxifens by human liver UDP-glucuronosyltransferases and sulfotransferases. Biochem. Pharmacol. 2002, 63, 1817-1830. [CrossRef]

26. Fromson, J.M.; Pearson, S.; Bramah, S. The metabolism of tamoxifen (I.C.I. 46,474). I: In laboratory animals. Xenobiotica 1973, 3 , 693-709. [CrossRef] [PubMed]

27. Lien, E.A.; Solheim, E.; Lea, O.A.; Lundgren, S.; Kvinnsland, S.; Ueland, P.M. Distribution of 4-hydroxy-N-desmethyltamoxifen and other tamoxifen metabolites in human biological fluids during tamoxifen treatment. Cancer Res. 1989, 49, $2175-2183$. [PubMed] 
28. Mürdter, T.E.; Schroth, W.; Bacchus-Gerybadze, L.; Winter, S.; Heinkele, G.; Simon, W.; Fasching, P.A.; Fehm, T.; The German, T.; Group, A.I.C.; et al. Activity Levels of Tamoxifen Metabolites at the Estrogen Receptor and the Impact of Genetic Polymorphisms of Phase I and II Enzymes on Their Concentration Levels in Plasma. Clin. Pharmacol. Ther. 2011, 89, 708-717. [CrossRef]

29. Wakeling, A.E.; Slater, S.R. Estrogen-receptor binding and biologic activity of tamoxifen and its metabolites. Cancer Treat. Rep. 1980, 64, 741-744.

30. Johnson, M.D.; Zuo, H.; Lee, K.H.; Trebley, J.P.; Rae, J.M.; Weatherman, R.V.; Desta, Z.; Flockhart, D.A.; Skaar, T.C. Pharmacological characterization of 4-hydroxy-N-desmethyl tamoxifen, a novel active metabolite of tamoxifen. Breast Cancer Res. Treat. 2004, 85, 151-159. [CrossRef]

31. Katzenellenbogen, B.S.; Norman, M.J.; Eckert, R.L.; Peltz, S.W.; Mangel, W.F. Bioactivities, estrogen receptor interactions, and plasminogen activator-inducing activities of tamoxifen and hydroxy-tamoxifen isomers in MCF-7 human breast cancer cells. Cancer Res. 1984, 44, 112-119.

32. Barginear, M.F.; Jaremko, M.; Peter, I.; Yu, C.; Kasai, Y.; Kemeny, M.; Raptis, G.; Desnick, R.J. Increasing Tamoxifen Dose in Breast Cancer Patients Based on CYP2D6 Genotypes and Endoxifen Levels: Effect on Active Metabolite Isomers and the Antiestrogenic Activity Score. Clin. Pharmacol. Ther. 2011, 90, 605-611. [CrossRef] [PubMed]

33. Murphy, C.S.; Parker, C.J.; McCague, R.; Jordan, V.C. Structure-activity relationships of nonisomerizable derivatives of tamoxifen: Importance of hydroxyl group and side chain positioning for biological activity. Mol. Pharm. 1991, 39, 421-428.

34. Lim, Y.C.; Desta, Z.; Flockhart, D.A.; Skaar, T.C. Endoxifen (4-hydroxy-N-desmethyl-tamoxifen) has anti-estrogenic effects in breast cancer cells with potency similar to 4-hydroxy-tamoxifen. Cancer Chemother. Pharmacol. 2005, 55, 471-478. [CrossRef] [PubMed]

35. Wu, X.; Hawse, J.R.; Subramaniam, M.; Goetz, M.P.; Ingle, J.N.; Spelsberg, T.C. The Tamoxifen Metabolite, Endoxifen, Is a Potent Antiestrogen that Targets Estrogen Receptor $\alpha$ for Degradation in Breast Cancer Cells. Cancer Res. 2009, 69, 1722-1727. [CrossRef]

36. Gong, I.Y.; Teft, W.A.; Ly, J.; Chen, Y.-H.; Alicke, B.; Kim, R.B.; Choo, E.F. Determination of clinically therapeutic endoxifen concentrations based on efficacy from human MCF7 breast cancer xenografts. Breast Cancer Res. Treat. 2013, 139, 61-69. [CrossRef] [PubMed]

37. De Vries Schultink, A.H.M.; Alexi, X.; van Werkhoven, E.; Madlensky, L.; Natarajan, L.; Flatt, S.W.; Zwart, W.; Linn, S.C.; Parker, B.A.; Wu, A.H.B.; et al. An Antiestrogenic Activity Score for tamoxifen and its metabolites is associated with breast cancer outcome. Breast Cancer Res. Treat. 2017, 161, 567-574. [CrossRef] [PubMed]

38. Löser, R.; Seibel, K.; Eppenberger, U. No loss of estrogenic or anti-estrogenic activity after demethylation of droloxifene (3-OHtamoxifen). Int. J. Cancer 1985, 36, 701-703. [CrossRef]

39. Helland, T.; Hagen, K.B.; Haugstoyl, M.E.; Kvaloy, J.T.; Lunde, S.; Lode, K.; Lind, R.A.; Gripsrud, B.H.; Jonsdottir, K.; Gjerde, J.; et al. Drug monitoring of tamoxifen metabolites predicts vaginal dryness and verifies a low discontinuation rate from the Norwegian Prescription Database. Breast Cancer Res. Treat. 2019, 177, 185-195. [CrossRef]

40. Helland, T.; Henne, N.; Bifulco, E.; Naume, B.; Borgen, E.; Kristensen, V.N.; Kvaløy, J.T.; Lash, T.L.; Alnæs, G.I.G.; van Schaik, R.H.; et al. Serum concentrations of active tamoxifen metabolites predict long-term survival in adjuvantly treated breast cancer patients. Breast Cancer Res. 2017, 19, 125. [CrossRef]

41. Love, R.R.; Desta, Z.; Flockhart, D.; Skaar, T.; Ogburn, E.T.; Ramamoorthy, A.; Uy, G.B.; Laudico, A.V.; Van Dinh, N.; Quang, L.H.; et al. CYP2D6 genotypes, endoxifen levels, and disease recurrence in 224 Filipino and Vietnamese women receiving adjuvant tamoxifen for operable breast cancer. SpringerPlus 2013, 2, 52. [CrossRef] [PubMed]

42. Sanchez-Spitman, A.; Dezentjé, V.; Swen, J.; Moes, D.J.A.R.; Böhringer, S.; Batman, E.; van Druten, E.; Smorenburg, C.; van Bochove, A.; Zeillemaker, A.; et al. Tamoxifen Pharmacogenetics and Metabolism: Results From the Prospective CYPTAM Study. J. Clin. Oncol. 2019, 37, 636-646. [CrossRef]

43. Goetz, M.P.; Suman, V.J.; Nakamura, Y.; Kiyotani, K.; Jordan, V.C.; Ingle, J.N. Tamoxifen Metabolism and Breast Cancer Recurrence: A Question Unanswered by CYPTAM. J. Clin. Oncol. Off. J. Am. Soc. Clin. Oncol. 2019, 37, 1982-1983. [CrossRef] [PubMed]

44. Brauch, H.; Schroth, W.; Murdter, T.; Schwab, M. Tamoxifen Pharmacogenetics and Metabolism: The Same Is Not the Same. J. Clin. Oncol. Off. J. Am. Soc. Clin. Oncol. 2019, 37, 1981-1982. [CrossRef] [PubMed]

45. Neven, P.; Jongen, L.; Lintermans, A.; Van Asten, K.; Blomme, C.; Lambrechts, D.; Poppe, A.; Wildiers, H.; Dieudonne, A.S.; Brouckaert, O.; et al. Tamoxifen Metabolism and Efficacy in Breast Cancer: A Prospective Multicenter Trial. Clin. Cancer Res. Off. J. Am. Assoc. Cancer Res. 2018, 24, 2312-2318. [CrossRef]

46. Tamura, K.; Imamura, C.K.; Takano, T.; Saji, S.; Yamanaka, T.; Yonemori, K.; Takahashi, M.; Tsurutani, J.; Nishimura, R.; Sato, K.; et al. CYP2D6 Genotype-Guided Tamoxifen Dosing in Hormone Receptor-Positive Metastatic Breast Cancer (TARGET-1): A Randomized, Open-Label, Phase II Study. J. Clin. Oncol. 2020, 38, 558-566. [CrossRef] [PubMed]

47. Johansson, H.; Gandini, S.; Serrano, D.; Gjerde, J.; Lattanzi, M.; Macis, D.; Guerrieri-Gonzaga, A.; Aristarco, V.; Mellgren, G.; Lien, E.; et al. A pooled analysis of CYP2D6 genotype in breast cancer prevention trials of low-dose tamoxifen. Breast Cancer Res. Treat. 2016, 159, 97-108. [CrossRef]

48. Engstrøm, M.J.; Opdahl, S.; Hagen, A.I.; Romundstad, P.R.; Akslen, L.A.; Haugen, O.A.; Vatten, L.J.; Bofin, A.M. Molecular subtypes, histopathological grade and survival in a historic cohort of breast cancer patients. Breast Cancer Res. Treat. 2013, 140, 463-473. [CrossRef] 
49. Sanchez-Spitman, A.B.; Moes, D.A.R.; Swen, J.J.; Dezentjé, V.O.; Lambrechts, D.; Neven, P.; Gelderblom, H.; Guchelaar, H.J. Exposure-response analysis of endoxifen serum concentrations in early-breast cancer. Cancer Chemother. Pharmacol. 2020, 85, 1141-1152. [CrossRef]

50. Ribelles, N.; Perez-Villa, L.; Jerez, J.M.; Pajares, B.; Vicioso, L.; Jimenez, B.; de Luque, V.; Franco, L.; Gallego, E.; Marquez, A.; et al. Pattern of recurrence of early breast cancer is different according to intrinsic subtype and proliferation index. Breast Cancer Res. 2013, 15, R98. [CrossRef]

51. Robinson, D.R.; Wu, Y.M.; Vats, P.; Su, F.; Lonigro, R.J.; Cao, X.; Kalyana-Sundaram, S.; Wang, R.; Ning, Y.; Hodges, L.; et al. Activating ESR1 mutations in hormone-resistant metastatic breast cancer. Nat. Genet. 2013, 45, 1446-1451. [CrossRef]

52. Kudela, E.; Samec, M.; Koklesova, L.; Liskova, A.; Kubatka, P.; Kozubik, E.; Rokos, T.; Pribulova, T.; Gabonova, E.; Smolar, M.; et al. miRNA Expression Profiles in Luminal A Breast Cancer-Implications in Biology, Prognosis, and Prediction of Response to Hormonal Treatment. Int. J. Mol. Sci. 2020, 21, 7691. [CrossRef]

53. Johnston, S.R.; Saccani-Jotti, G.; Smith, I.E.; Salter, J.; Newby, J.; Coppen, M.; Ebbs, S.R.; Dowsett, M. Changes in estrogen receptor, progesterone receptor, and pS2 expression in tamoxifen-resistant human breast cancer. Cancer Res. 1995, 55, 3331-3338. [PubMed]

54. Regan, M.M.; Leyland-Jones, B.; Bouzyk, M.; Pagani, O.; Tang, W.; Kammler, R.; Dell'Orto, P.; Biasi, M.O.; Thürlimann, B.; Lyng, M.B.; et al. CYP2D6 Genotype and Tamoxifen Response in Postmenopausal Women with Endocrine-Responsive Breast Cancer: The Breast International Group 1-98 Trial. J. Natl. Cancer Inst. 2012. [CrossRef]

55. Rae, J.M.; Drury, S.; Hayes, D.F.; Stearns, V.; Thibert, J.N.; Haynes, B.P.; Salter, J.; Sestak, I.; Cuzick, J.; Dowsett, M. CYP2D6 and UGT2B7 genotype and risk of recurrence in tamoxifen-treated breast cancer patients. J. Natl. Cancer Inst. 2012, 104, 452-460. [CrossRef]

56. Referenced from the NCCN Clinical Practice Guidelines in Oncology (NCCN Guidelines ${ }^{\circledR}$ ) for Breast Cancer V.1.2019. ${ }^{\odot}$ National Comprehensive Cancer Network, Inc. 2019. National Comprehensive Cancer Network ${ }^{\circledR}, \mathrm{NCCN}^{\circledR}, \mathrm{NCCN}$ Guidelines ${ }^{\circledR}$, and all other NCCN Content are trademarks owned by the National Comprehensive Cancer Network, Inc. Available online: www.nccn.org (accessed on 27 June 2019).

57. Goetz, M.P.; Sangkuhl, K.; Guchelaar, H.-J.; Schwab, M.; Province, M.; Whirl-Carrillo, M.; Symmans, W.F.; McLeod, H.L.; Ratain, M.J.; Zembutsu, H.; et al. Clinical Pharmacogenetics Implementation Consortium (CPIC) Guideline for CYP2D6 and Tamoxifen Therapy. Clin. Pharmacol. Ther. 2018, 103, 770-777. [CrossRef] [PubMed]

58. Harris, L.; Ismaila, N.; McShane, L.; Andre, F.; Collyar, D.; Gonzalez-Angulo, A.; Hammond, E.; Kuderer, N.; Liu, M.; Mennel, R.; et al. Use of Biomarkers to Guide Decisions on Adjuvant Systemic Therapy for Women With Early-Stage Invasive Breast Cancer: American Society of Clinical Oncology Clinical Practice Guideline. J. Clin. Oncol. Off. J. Am. Soc. Clin. Oncol. 2016, 34, 1134-1150. [CrossRef]

59. Schroth, W.; Antoniadou, L.; Fritz, P.; Schwab, M.; Muerdter, T.; Zanger, U.M.; Simon, W.; Eichelbaum, M.; Brauch, H. Breast Cancer Treatment Outcome With Adjuvant Tamoxifen Relative to Patient CYP2D6 and CYP2C19 Genotypes. J. Clin. Oncol. 2007, 25, 5187-5193. [CrossRef]

60. Wegman, P.; Elingarami, S.; Carstensen, J.; Stal, O.; Nordenskjold, B.; Wingren, S. Genetic variants of CYP3A5, CYP2D6, SULT1A1, UGT2B15 and tamoxifen response in postmenopausal patients with breast cancer. Breast Cancer Res. 2007, 9, R7. [CrossRef] [PubMed]

61. Andrea, G. Pharmacogene Variation Consortium (PharmVar). Available online: https://www.pharmvar.org/gene/CYP2D6 (accessed on 13 July 2020).

62. (PharmVar), P.V.C. Human Cytochrome P450 (CYP) Allele Nomenclature Database. 2020. Available online: www.PharmVar.org (accessed on 15 January 2021).

63. Caudle, K.E.; Sangkuhl, K.; Whirl-Carrillo, M.; Swen, J.J.; Haidar, C.E.; Klein, T.E.; Gammal, R.S.; Relling, M.V.; Scott, S.A.; Hertz, D.L.; et al. Standardizing CYP2D6 Genotype to Phenotype Translation: Consensus Recommendations from the Clinical Pharmacogenetics Implementation Consortium and Dutch Pharmacogenetics Working Group. Clin. Transl. Sci. 2020, 13, 116-124. [CrossRef] [PubMed]

64. Hicks, J.K.; Swen, J.J.; Gaedigk, A. Challenges in CYP2D6 phenotype assignment from genotype data: A critical assessment and call for standardization. Curr. Drug Metab. 2014, 15, 218-232. [CrossRef]

65. Gjerde, J.; Hauglid, M.; Breilid, H.; Lundgren, S.; Varhaug, J.E.; Kisanga, E.R.; Mellgren, G.; Steen, V.M.; Lien, E.A. Effects of CYP2D6 and SULT1A1 genotypes including SULT1A1 gene copy number on tamoxifen metabolism. Ann. Oncol. 2007, $19,56-61$. [CrossRef] [PubMed]

66. Hertz, D.L.; McLeod, H.L.; Irvin, W.J. Tamoxifen and CYP2D6: A contradiction of data. Oncologist 2012, 17, 620-630. [CrossRef] [PubMed]

67. Teft, W.A.; Gong, I.Y.; Dingle, B.; Potvin, K.; Younus, J.; Vandenberg, T.A.; Brackstone, M.; Perera, F.E.; Choi, Y.-H.; Zou, G.; et al. CYP3A4 and seasonal variation in vitamin D status in addition to CYP2D6 contribute to therapeutic endoxifen level during tamoxifen therapy. Breast Cancer Res. Treat. 2013, 139, 95-105. [CrossRef]

68. Hennig, E.E.; Piatkowska, M.; Karczmarski, J.; Goryca, K.; Brewczynska, E.; Jazwiec, R.; Kluska, A.; Omiotek, R.; Paziewska, A.; Dadlez, M.; et al. Limited predictive value of achieving beneficial plasma (Z)-endoxifen threshold level by CYP2D6 genotyping in tamoxifen-treated Polish women with breast cancer. BMC Cancer 2015, 15, 570. [CrossRef] 
69. Antunes, M.V.; Linden, R.; Santos, T.V.; Wallemacq, P.; Haufroid, V.; Classen, J.F.; Andreolla, H.; Costa, N.; Fontanive, T.O.; Rosa, D.D. Endoxifen levels and its association with CYP2D6 genotype and phenotype: Evaluation of a southern Brazilian population under tamoxifen pharmacotherapy. Ther. Drug Monit. 2012, 34, 422-431. [CrossRef]

70. Puszkiel, A.; Arellano, C.; Vachoux, C.; Evrard, A.; Le Morvan, V.; Boyer, J.C.; Robert, J.; Delmas, C.; Dalenc, F.; Debled, M.; et al. Factors Affecting Tamoxifen Metabolism in Patients With Breast Cancer: Preliminary Results of the French PHACS Study. Clin. Pharmacol. Ther. 2019, 106, 585-595. [CrossRef]

71. Antunes, M.V.; de Oliveira, V.; Raymundo, S.; Staudt, D.E.; Gössling, G.; Biazús, J.V.; Cavalheiro, J.A.; Rosa, D.D.; Mathy, G.; Wallemacq, P.; et al. CYP3A4*22 is related to increased plasma levels of 4-hydroxytamoxifen and partially compensates for reduced CYP2D6 activation of tamoxifen. Pharmacogenomics 2015, 16, 601-617. [CrossRef] [PubMed]

72. Marcath, L.A.; Deal, A.M.; Van Wieren, E.; Danko, W.; Walko, C.M.; Ibrahim, J.G.; Weck, K.E.; Jones, D.R.; Desta, Z.; McLeod, H.L.; et al. Comprehensive assessment of cytochromes P450 and transporter genetics with endoxifen concentration during tamoxifen treatment. Pharm. Genom. 2017, 27, 402-409. [CrossRef]

73. Powers, J.L.; Buys, S.S.; Fletcher, D.; Melis, R.; Johnson-Davis, K.L.; Lyon, E.; Malmberg, E.M.; McMillin, G.A. Multigene and Drug Interaction Approach for Tamoxifen Metabolite Patterns Reveals Possible Involvement of CYP2C9, CYP2C19, and ABCB1. J. Clin. Pharmacol. 2016, 56, 1570-1581. [CrossRef] [PubMed]

74. Lim, H.S.; Ju Lee, H.; Seok Lee, K.; Sook Lee, E.; Jang, I.J.; Ro, J. Clinical implications of CYP2D6 genotypes predictive of tamoxifen pharmacokinetics in metastatic breast cancer. J. Clin. Oncol. Off. J. Am. Soc. Clin. Oncol. 2007, 25, 3837-3845. [CrossRef]

75. Fox, P.; Balleine, R.L.; Lee, C.; Gao, B.; Balakrishnar, B.; Menzies, A.M.; Yeap, S.H.; Ali, S.S.; Gebski, V.; Provan, P.; et al. Dose Escalation of Tamoxifen in Patients with Low Endoxifen Level: Evidence for Therapeutic Drug Monitoring-The TADE Study. Clin. Cancer Res. Off. J. Am. Assoc. Cancer Res. 2016, 22, 3164-3171. [CrossRef] [PubMed]

76. Safgren, S.L.; Suman, V.J.; Kosel, M.L.; Gilbert, J.A.; Buhrow, S.A.; Black, J.L.; Northfelt, D.W.; Modak, A.S.; Rosen, D.; Ingle, J.N.; et al. Evaluation of CYP2D6 enzyme activity using a 13C-dextromethorphan breath test in women receiving adjuvant tamoxifen. Pharm. Genom. 2015, 25, 157-163. [CrossRef] [PubMed]

77. Kiyotani, K.; Mushiroda, T.; Imamura, C.K.; Tanigawara, Y.; Hosono, N.; Kubo, M.; Sasa, M.; Nakamura, Y.; Zembutsu, H. Dose-adjustment study of tamoxifen based on CYP2D6 genotypes in Japanese breast cancer patients. Breast Cancer Res. Treat. 2012, 131, 137-145. [CrossRef] [PubMed]

78. Jr, W.J.I.; Walko, C.M.; Weck, K.E.; Ibrahim, J.G.; Chiu, W.K.; Dees, E.C.; Moore, S.G.; Olajide, O.A.; Graham, M.L.; Canale, S.T.; et al. Genotype-Guided Tamoxifen Dosing Increases Active Metabolite Exposure in Women With Reduced CYP2D6 Metabolism: A Multicenter Study. J. Clin. Oncol. 2011, 29, 3232-3239. [CrossRef]

79. Ximenez, J.P.B.; de Andrade, J.M.; Marques, M.P.; Coelho, E.B.; Suarez-Kurtz, G.; Lanchote, V.L. Hormonal status affects plasma exposure of tamoxifen and its main metabolites in tamoxifen-treated breast cancer patients. BMC Pharm. Toxicol 2019, $20,81$. [CrossRef] [PubMed]

80. Woo, H.I.; Lee, S.K.; Kim, J.; Kim, S.W.; Yu, J.; Bae, S.Y.; Lee, J.E.; Nam, S.J.; Lee, S.-Y. Variations in plasma concentrations of tamoxifen metabolites and the effects of genetic polymorphisms on tamoxifen metabolism in Korean patients with breast cancer. Oncotarget 2017, 8, 100296-100311. [CrossRef]

81. Areepium, N.; Panomvana, D.; Rungwanonchai, P.; Sathaporn, S.; Voravud, N. Effects of CYP2D6 and UGT2B7 polymorphisms on pharmacokinetics of tamoxifen in Thai breast cancer patients. Breast Cancer 2013, 5, 73-78. [CrossRef]

82. Fernandez-Santander, A.; Gaibar, M.; Novillo, A.; Romero-Lorca, A.; Rubio, M.; Chicharro, L.M.; Tejerina, A.; Bandres, F. Relationship between genotypes Sult1a2 and Cyp2d6 and tamoxifen metabolism in breast cancer patients. PLoS ONE 2013, 8, e70183. [CrossRef]

83. Thorén, L.; Lindh, J.D.; Ackehed, G.; Kringen, M.K.; Hall, P.; Bergh, J.; Molden, E.; Margolin, S.; Eliasson, E. Impairment of endoxifen formation in tamoxifen-treated premenopausal breast cancer patients carrying reduced-function CYP2D6 alleles. Br. J. Clin. Pharm. 2020. [CrossRef]

84. Khan, B.A.; Robinson, R.; Fohner, A.E.; Muzquiz, L.I.; Schilling, B.D.; Beans, J.A.; Olnes, M.J.; Trawicki, L.; Frydenlund, H.; Laukes, C.; et al. Cytochrome P450 Genetic Variation Associated with Tamoxifen Biotransformation in American Indian and Alaska Native People. Clin. Transl. Sci. 2018, 11, 312-321. [CrossRef] [PubMed]

85. Schroth, W.; Hamann, U.; Fasching, P.A.; Dauser, S.; Winter, S.; Eichelbaum, M.; Schwab, M.; Brauch, H. CYP2D6 polymorphisms as predictors of outcome in breast cancer patients treated with tamoxifen: Expanded polymorphism coverage improves risk stratification. Clin. Cancer Res. Off. J. Am. Assoc. Cancer Res. 2010, 16, 4468-4477. [CrossRef]

86. He, Y.; Hoskins, J.M.; McLeod, H.L. Copy number variants in pharmacogenetic genes. Trends Mol. Med. 2011, 17, 244-251. [CrossRef]

87. Schroth, W.; Winter, S.; Mürdter, T.; Schaeffeler, E.; Eccles, D.; Eccles, B.; Chowbay, B.; Khor, C.C.; Tfayli, A.; Zgheib, N.K.; et al. Improved Prediction of Endoxifen Metabolism by CYP2D6 Genotype in Breast Cancer Patients Treated with Tamoxifen. Front Pharm. 2017, 8, 582. [CrossRef] [PubMed]

88. Gaedigk, A.; Simon, S.D.; Pearce, R.E.; Bradford, L.D.; Kennedy, M.J.; Leeder, J.S. The CYP2D6 activity score: Translating genotype information into a qualitative measure of phenotype. Clin. Pharmacol. Ther. 2008, 83, 234-242. [CrossRef]

89. Kiyotani, K.; Mushiroda, T.; Imamura, C.K.; Hosono, N.; Tsunoda, T.; Kubo, M.; Tanigawara, Y.; Flockhart, D.A.; Desta, Z.; Skaar, T.C.; et al. Significant effect of polymorphisms in CYP2D6 and ABCC2 on clinical outcomes of adjuvant tamoxifen therapy for breast cancer patients. J. Clin. Oncol. Off. J. Am. Soc. Clin. Oncol. 2010, 28, 1287-1293. [CrossRef] [PubMed] 
90. Lim, J.S.; Chen, X.A.; Singh, O.; Yap, Y.S.; Ng, R.C.; Wong, N.S.; Wong, M.; Lee, E.J.; Chowbay, B. Impact of CYP2D6, CYP3A5, CYP2C9 and CYP2C19 polymorphisms on tamoxifen pharmacokinetics in Asian breast cancer patients. Br. J. Clin. Pharm. 2011, 71,737-750. [CrossRef]

91. Helland, T.; Baurley, J.; Thomas-Jean, F.; Mellgren, G.; Swenn, J.; Brauch, H.; Gaedigk, A.; Hertz, D. Consensus CYP2D6 translation system improves explanation of tamoxifen bioactivation in analysis of 15 multi-racial cohorts. In Proceedings of the American Society of Clinical Pharmacology and Therapeutics Annual Meeting, Houston, TX, USA, 17-21 March 2020.

92. Haque, R.; Shi, J.; Schottinger, J.E.; Ahmed, S.A.; Cheetham, T.C.; Chung, J.; Avila, C.; Kleinman, K.; Habel, L.A.; Fletcher, S.W.; et al. Tamoxifen and Antidepressant Drug Interaction in a Cohort of 16,887 Breast Cancer Survivors. J. Natl. Cancer Inst. 2016, 108. [CrossRef]

93. Pistilli, B.; Paci, A.; Ferreira, A.R.; Meglio, A.D.; Poinsignon, V.; Bardet, A.; Menvielle, G.; Dumas, A.; Pinto, S.; Dauchy, S.; et al. Serum Detection of Nonadherence to Adjuvant Tamoxifen and Breast Cancer Recurrence Risk. J. Clin. Oncol. 2020, 38, $2762-2772$. [CrossRef]

94. Mueller-Schoell, A.; Klopp-Schulze, L.; Michelet, R.; van Dyk, M.; Mürdter, T.E.; Schwab, M.; Joerger, M.; Huisinga, W.; Mikus, G.; Kloft, C. Simulation-Based Assessment of the Impact of Non-Adherence on Endoxifen Target Attainment in Different Tamoxifen Dosing Strategies. Pharmaceuticals 2021, 14, 115. [CrossRef]

95. Nardin, J.M.; Schroth, W.; Almeida, T.A.; Mürdter, T.; Picolotto, S.; Vendramini, E.C.L.; Hoppe, R.; Kogin, J.P.; Miqueleto, D.; de Moraes, S.D.R.; et al. The Influences of Adherence to Tamoxifen and CYP2D6 Pharmacogenetics on Plasma Concentrations of the Active Metabolite (Z)-Endoxifen in Breast Cancer. Clin. Transl. Sci. 2020, 13, 284-292. [CrossRef]

96. Jager, N.G.; Rosing, H.; Linn, S.C.; Schellens, J.H.; Beijnen, J.H. Importance of highly selective LC-MS/MS analysis for the accurate quantification of tamoxifen and its metabolites: Focus on endoxifen and 4-hydroxytamoxifen. Breast Cancer Res. Treat. 2012, 133, 793-798. [CrossRef]

97. Mueller-Schoell, A.; Klopp-Schulze, L.; Schroth, W.; Mürdter, T.; Michelet, R.; Brauch, H.; Huisinga, W.; Joerger, M.; Neven, P.; Koolen, S.L.W.; et al. Obesity Alters Endoxifen Plasma Levels in Young Breast Cancer Patients: A Pharmacometric Simulation Approach. Clin. Pharmacol. Ther. 2020, 108, 661-670. [CrossRef]

98. Lien, E.A.; Søiland, H.; Lundgren, S.; Aas, T.; Steen, V.M.; Mellgren, G.; Gjerde, J. Serum concentrations of tamoxifen and its metabolites increase with age during steady-state treatment. Breast Cancer Res. Treat. 2013, 141, 243-248. [CrossRef] [PubMed]

99. Gjerde, J.; Geisler, J.; Lundgren, S.; Ekse, D.; Varhaug, J.E.; Mellgren, G.; Steen, V.M.; Lien, E.A. Associations between tamoxifen, estrogens, and FSH serum levels during steady state tamoxifen treatment of postmenopausal women with breast cancer. BMC Cancer 2010, 10, 313. [CrossRef] [PubMed]

100. Martinez de Dueñas, E.; Ochoa Aranda, E.; Blancas Lopez-Barajas, I.; Ferrer Magdalena, T.; Bandrés Moya, F.; Chicharro García, L.M.; Gómez Capilla, J.A.; Zafra Ceres, M.; de Haro, T.; Romero Llorens, R.; et al. Adjusting the dose of tamoxifen in patients with early breast cancer and CYP2D6 poor metabolizer phenotype. Breast 2014, 23, 400-406. [CrossRef] [PubMed]

101. Xu, Y.; Sun, Y.; Yao, L.; Shi, L.; Wu, Y.; Ouyang, T.; Li, J.; Wang, T.; Fan, Z.; Fan, T.; et al. Association between CYP2D6 *10 genotype and survival of breast cancer patients receiving tamoxifen treatment. Ann. Oncol. 2008, 19, 1423-1429. [CrossRef]

102. Lei, L.; Wang, X.; Wu, X.D.; Wang, Z.; Chen, Z.H.; Zheng, Y.B.; Wang, X.J. Association of CYP2D6*10 (c.100C >T) polymorphisms with clinical outcome of breast cancer after tamoxifen adjuvant endocrine therapy in Chinese population. Am. J. Transl. Res. 2016, 8, 3585-3592.

103. Paine, M.F.; Hart, H.L.; Ludington, S.S.; Haining, R.L.; Rettie, A.E.; Zeldin, D.C. The human intestinal cytochrome P450 "pie". Drug Metab. Dispos. 2006, 34, 880-886. [CrossRef]

104. Boocock, D.J.; Brown, K.; Gibbs, A.H.; Sanchez, E.; Turteltaub, K.W.; White, I.N. Identification of human CYP forms involved in the activation of tamoxifen and irreversible binding to DNA. Carcinogenesis 2002, 23, 1897-1901. [CrossRef]

105. Coller, J.K.; Krebsfaenger, N.; Klein, K.; Endrizzi, K.; Wolbold, R.; Lang, T.; Nüssler, A.; Neuhaus, P.; Zanger, U.M.; Eichelbaum, M.; et al. The influence of CYP2B6, CYP2C9 and CYP2D6 genotypes on the formation of the potent antioestrogen Z-4-hydroxytamoxifen in human liver. Br. J. Clin. Pharm. 2002, 54, 157-167. [CrossRef] [PubMed]

106. Botton, M.R.; Whirl-Carrillo, M.; Del Tredici, A.L.; Sangkuhl, K.; Cavallari, L.H.; Agúndez, J.A.G.; Duconge, J.; Lee, M.T.M.; Woodahl, E.L.; Claudio-Campos, K.; et al. PharmVar GeneFocus: CYP2C19. Clin. Pharmacol. Ther. 2021, 109, 352-366. [CrossRef] [PubMed]

107. Aquilante, C.L.; Niemi, M.; Gong, L.; Altman, R.B.; Klein, T.E. PharmGKB summary: Very important pharmacogene information for cytochrome P450, family 2, subfamily C, polypeptide 8. Pharm. Genom. 2013, 23, 721-728. [CrossRef] [PubMed]

108. Gao, Y.; Liu, D.; Wang, H.; Zhu, J.; Chen, C. Functional characterization of five CYP2C8 variants and prediction of CYP2C8 genotype-dependent effects on in vitro and in vivo drug-drug interactions. Xenobiotica 2010, 40, 467-475. [CrossRef] [PubMed]

109. Elens, L.; van Gelder, T.; Hesselink, D.A.; Haufroid, V.; van Schaik, R.H. CYP3A4*22: Promising newly identified CYP3A4 variant allele for personalizing pharmacotherapy. Pharmacogenomics 2013, 14, 47-62. [CrossRef]

110. Wang, D.; Guo, Y.; Wrighton, S.A.; Cooke, G.E.; Sadee, W. Intronic polymorphism in CYP3A4 affects hepatic expression and response to statin drugs. Pharm. J. 2011, 11, 274-286. [CrossRef]

111. Baxter, S.D.; Teft, W.A.; Choi, Y.H.; Winquist, E.; Kim, R.B. Tamoxifen-associated hot flash severity is inversely correlated with endoxifen concentration and CYP3A4*22. Breast Cancer Res. Treat. 2014, 145, 419-428. [CrossRef]

112. Sanchez Spitman, A.B.; Moes, D.; Gelderblom, H.; Dezentje, V.O.; Swen, J.J.; Guchelaar, H.J. Effect of CYP3A4*22, CYP3A5*3, and CYP3A combined genotypes on tamoxifen metabolism. Eur. J. Clin. Pharm. 2017, 73, 1589-1598. [CrossRef] 
113. Sensorn, I.; Sirachainan, E.; Chamnanphon, M.; Pasomsub, E.; Trachu, N.; Supavilai, P.; Sukasem, C.; Pinthong, D. Association of CYP3A4/5, ABCB1 and ABCC2 polymorphisms and clinical outcomes of Thai breast cancer patients treated with tamoxifen. Pharmgenomics Pers. Med. 2013, 6, 93-98. [CrossRef]

114. Apellániz-Ruiz, M.; Inglada-Pérez, L.; Naranjo, M.E.; Sánchez, L.; Mancikova, V.; Currás-Freixes, M.; de Cubas, A.A.; Comino-Méndez, I.; Triki, S.; Rebai, A.; et al. High frequency and founder effect of the CYP3A4*20 loss-of-function allele in the Spanish population classifies CYP3A4 as a polymorphic enzyme. Pharm. J. 2015, 15, 288-292. [CrossRef]

115. Tucker, A.N.; Tkaczuk, K.A.; Lewis, L.M.; Tomic, D.; Lim, C.K.; Flaws, J.A. Polymorphisms in cytochrome P4503A5 (CYP3A5) may be associated with race and tumor characteristics, but not metabolism and side effects of tamoxifen in breast cancer patients. Cancer Lett. 2005, 217, 61-72. [CrossRef]

116. Charoenchokthavee, W.; Areepium, N.; Panomvana, D.; Sriuranpong, V. Effects of CYP2D6 and CYP3A5 polymorphisms on tamoxifen and its metabolites in Thai breast cancer patients. Breast Cancer (Dove Med. Press) 2017, 9, 249-256. [CrossRef]

117. Thota, K.; Prasad, K.; Basaveswara Rao, M.V. Detection of Cytochrome P450 Polymorphisms in Breast Cancer Patients May Impact on Tamoxifen Therapy. Asian Pac. J. Cancer Prev. 2018, 19, 343-350. [CrossRef]

118. Nowell, S.; Falany, C.N. Pharmacogenetics of human cytosolic sulfotransferases. Oncogene 2006, 25, 1673-1678. [CrossRef] [PubMed]

119. Sanchez-Spitman, A.B.; Dezentjé, V.O.; Swen, J.J.; Moes, D.; Gelderblom, H.; Guchelaar, H.J. Genetic polymorphisms of 3'untranslated region of SULT1A1 and their impact on tamoxifen metabolism and efficacy. Breast Cancer Res. Treat. 2018, 172, 401-411. [CrossRef]

120. Nowell, S.; Sweeney, C.; Winters, M.; Stone, A.; Lang, N.P.; Hutchins, L.F.; Kadlubar, F.F.; Ambrosone, C.B. Association between sulfotransferase 1A1 genotype and survival of breast cancer patients receiving tamoxifen therapy. J. Natl. Cancer Inst. 2002, 94, 1635-1640. [CrossRef]

121. Carlini, E.J.; Raftogianis, R.B.; Wood, T.C.; Jin, F.; Zheng, W.; Rebbeck, T.R.; Weinshilboum, R.M. Sulfation pharmacogenetics: SULT1A1 and SULT1A2 allele frequencies in Caucasian, Chinese and African-American subjects. Pharmacogenetics 2001, 11, 57-68. [CrossRef] [PubMed]

122. Lazarus, P.; Sun, D. Potential role of UGT pharmacogenetics in cancer treatment and prevention: Focus on tamoxifen and aromatase inhibitors. Drug Metab. Rev. 2010, 42, 182-194. [CrossRef]

123. Sutiman, N.; Lim, J.S.L.; Muerdter, T.E.; Singh, O.; Cheung, Y.B.; Ng, R.C.H.; Yap, Y.S.; Wong, N.S.; Ang, P.C.S.; Dent, R.; et al. Pharmacogenetics of UGT1A4, UGT2B7 and UGT2B15 and Their Influence on Tamoxifen Disposition in Asian Breast Cancer Patients. Clin. Pharm. 2016, 55, 1239-1250. [CrossRef] [PubMed]

124. Blevins-Primeau, A.S.; Sun, D.; Chen, G.; Sharma, A.K.; Gallagher, C.J.; Amin, S.; Lazarus, P. Functional significance of UDPglucuronosyltransferase variants in the metabolism of active tamoxifen metabolites. Cancer Res. 2009, 69, 1892-1900. [CrossRef]

125. Romero-Lorca, A.; Novillo, A.; Gaibar, M.; Bandres, F.; Fernandez-Santander, A. Impacts of the Glucuronidase Genotypes UGT1A4, UGT2B7, UGT2B15 and UGT2B17 on Tamoxifen Metabolism in Breast Cancer Patients. PLoS ONE 2015, 10, e0132269. [CrossRef]

126. Klopp-Schulze, L.; Joerger, M.; Wicha, S.G.; ter Heine, R.; Csajka, C.; Parra-Guillen, Z.P.; Kloft, C. Exploiting Pharmacokinetic Models of Tamoxifen and Endoxifen to Identify Factors Causing Subtherapeutic Concentrations in Breast Cancer Patients. Clin. Pharmacokinet. 2018, 57, 229-242. [CrossRef]

127. Puszkiel, A.; Arellano, C.; Vachoux, C.; Evrard, A.; Le Morvan, V.; Boyer, J.C.; Robert, J.; Delmas, C.; Dalenc, F.; Debled, M.; et al. Model-Based Quantification of Impact of Genetic Polymorphisms and Co-Medications on Pharmacokinetics of Tamoxifen and Six Metabolites in Breast Cancer. Clin. Pharmacol. Ther. 2020. [CrossRef] [PubMed]

128. Klopp-Schulze, L.; Mueller-Schoell, A.; Neven, P.; Koolen, S.L.W.; Mathijssen, R.H.J.; Joerger, M.; Kloft, C. Integrated Data Analysis of Six Clinical Studies Points Toward Model-Informed Precision Dosing of Tamoxifen. Front. Pharmacol. $2020,11$. [CrossRef] [PubMed]

129. Van der Lee, M.; Allard, W.G.; Vossen, R.H.A.M.; Baak-Pablo, R.F.; Menafra, R.; Deiman, B.A.L.M.; Deenen, M.J.; Neven, P.; Johansson, I.; Gastaldello, S.; et al. A unifying model to predict variable drug response for personalised medicine. bioRxiv 2003. [CrossRef] 